\title{
Performance of Magnesia-modified Sodium Carbonate-activated Slag/Fly ash Concrete
}

\author{
Ahmed Abdalqader ${ }^{a^{*}}$, Fei Jin ${ }^{\mathrm{b}}$, Abir Al-Tabbaa ${ }^{\mathrm{c}}$ \\ (a) Department of Engineering, University College of Applied Sciences, Tel Elhawa, Gaza, \\ P.O. Box 1415, Palestine \\ (b) Department of Engineering, University of Glasgow Singapore, 10 Dover Road, Singapore \\ 138683. \\ (c) Department of Engineering, University of Cambridge, Trumpington Road, Cambridge \\ CB2 1PZ, United Kingdom \\ * Corresponding author: Ahmed Abdalqader. Email: aalqader@gmail.com
}

Declarations of interest: none 


\begin{abstract}
Various innovative research in the cement industry is looking into improving its environmental sustainability. Sodium carbonate-activated slag/fly ash (NC-SF) binders has recently evolved as a potentially more sustainable binding materials than both Portland cement and conventional alkali activated materials such as sodium silicate and sodium hydroxide activated materials. The reaction mechanism and some microstructural properties of NC-SF cements have been a major area of research recently. However, very few studies have scaled up the investigation of these binders into concrete specimens. This paper, therefore, provides new insight into the strength development and the durability performance of NC-SF concrete and MgO-modified NC-SF concrete. Concrete testing included measurements of compressive strength, split tensile strength, water absorption, depth of carbonation, sulphate exposure, acid exposure and elevated-temperature exposure. Microstructure studies were conducted using Powder X-Ray diffraction (PXRD), Thermogravimetric analysis (TGA) and Attenuated Total Reflectance Fourier Transform Infrared spectroscopy (ATR-FTIR). It is concluded that NC-SF concrete mixes develop acceptable mechanical strength and demonstrate high resistance to sulphate attack. They also showed higher resistance to acid attack than the control mix based on sodium silicate-activated slag concrete. Here, emphasis is placed on the potential of developing NC-SF concrete with excellent performance and less complicated production methods as well as a low carbon footprint. It is also found that the use of reactive $\mathrm{MgO}$ enhanced the strength development of NC-SF concrete as well as its resistance to acid and carbonation.
\end{abstract}

Keywords: Alkali Activated Materials, Slag, Fly Ash, Sodium Carbonate, Reactive Magnesia, Sustainable Concrete. 


\begin{tabular}{|c|c|}
\hline $\mathrm{AACs}$ & Alkali-Activated Cements \\
\hline AAFA & Alkali-Activated Fly Ash \\
\hline AAMs & Alkali Activated Materials \\
\hline AAS & Alkali-Activated Slag \\
\hline AASF & Alkali-Activated Slag/Fly Ash \\
\hline ATR-FTIR & Attenuated Total Reflectance Fourier Transform Infrared Spectroscopy \\
\hline $\mathrm{BS}$ & British Standards \\
\hline $\mathrm{Ca}_{2} \mathrm{Mg}\left[\mathrm{Si}_{2} \mathrm{O}_{7}\right]$ & Akermanite \\
\hline $\mathrm{Ca}_{6} \mathrm{Al}_{2}\left(\mathrm{SO}_{4}\right)_{3}(\mathrm{OH})_{12 .} .26 \mathrm{H}_{2} \mathrm{O}$ & Ettringite \\
\hline $\mathrm{CaCO}_{3}$ & Calcite \\
\hline $\mathrm{CaMgSi}_{2} \mathrm{O}_{6}$ & Diopside \\
\hline $\mathrm{CaSiO}_{3}$ & Wollastonite \\
\hline $\mathrm{CO}_{2}$ & Carbon Dioxide \\
\hline C-A-S-H & Calcium Aluminate Silicate Hydrate \\
\hline C-S-H & Calcium Silicate Hydrate \\
\hline DTG & Differential Thermogravimetric \\
\hline $\mathrm{HCl}$ & Hydrochloric Acid \\
\hline $\mathrm{Ht}$ & Hydrotalcite \\
\hline $\mathrm{MgAl}_{2} \mathrm{O}_{4}$ & Spinel \\
\hline $\mathrm{MgO}$ & Reactive Magnesia \\
\hline $\mathrm{MgSO}_{4}$ & Magnesium Sulphate Solution \\
\hline $\mathrm{MPa}$ & Megapascal (N/Mm²) \\
\hline Ms & Activator Modulus \\
\hline $\mathrm{Na}_{2} \mathrm{SO}_{4}$ & Sodium Sulphate \\
\hline $\mathrm{Na}_{2} \mathrm{CO}_{3} \cdot 10 \mathrm{H}_{2} \mathrm{O}$ & Natron \\
\hline
\end{tabular}


$\mathrm{NaCl}$

$\mathrm{NaCO}_{3} \cdot \mathrm{H}_{2} \mathrm{O}$

$\mathrm{NaHCO}_{3}$

N-A-S-H

$\mathrm{NC}$

NC-SF

$\mathrm{NH}$

NS

PC

PDF

PXRD

RH

SPs

TGA
Sodium Chloride

Thermonatrite

Nahcolite

Sodium Aluminate Silicate Hydrate

Sodium Carbonate

Sodium Carbonate-Activated Slag/Fly Ash

Sodium Hydroxide

Sodium Silicate

Portland Cement

Powder Diffraction File

Powder X-Ray Diffraction

Relative Humidity

Superplasticisers

Thermogravimetric Analysis 


\section{Introduction}

The production of Portland cement (PC) is responsible for 5-8\% of anthropogenic carbon dioxide $\left(\mathrm{CO}_{2}\right)$ emissions [1]. Therefore, extensive research efforts are made on exploring alternatives to PC to reduce the negative impact on the environment from the cement and concrete industry, in which alkali-activated cements (AACs) show significant promise. Readily-available commercial by-products such as fly ash and blastfurnace slag have been utilised in AACs. Alkali-activated slag (AAS) and alkali-activated fly ash (AAFA) binders have both shown excellent performance and technical advantages compared to PC such as high compressive strength and high resistance to chemicals. Nevertheless, each material has its own demerits such as high levels of drying shrinkage for AAS binders and the need for thermal treatment for AAFA binders.

A growing attention to blend slag and fly ash was driven by the accumulated understanding of the reaction mechanisms, mechanical performance and durability of each system. The combination of these two materials has evolved to counterbalance the disadvantages of the activation of each material alone. It is expected that slag/fly ash system would offer a better interaction between mechanical strength and durability, benefiting from the stable coexistence of the characteristic reaction products of AAS (mainly, Calcium Aluminate Silicate Hydrate, C-A-S-H, gel) and AAFA (mainly Sodium Aluminate Silicate Hydrate, N-A-S-H, gel) [2,3]. This strategy will also resolve the issues of availability for a single raw material in some regions and will shed light on the utilisation of other aluminosilicate materials which may be inadequately reactive when activated alone.

Literature reveals that the first use of alkali-activated slag/fly ash (AASF) dates back to the work of Smith and Osborne in 1977 [2] on various types of AAC concretes including one mix with slag/fly ash ratio of 60/40. A few studies then investigated primarily the strength of AASF binders with limited S/F ratios. Since 2000, main research activities around AACs focused on either AAS or AAFA cements, while in the last decade, more attention has been paid to the reaction kinetics, products, microstructure as well as the engineering performance of AASF (pastes, mortars and concretes). Those have involved a wide range of slag/fly ash ratios, activator formulae, various liquid to binder ratios and different curing conditions [4-12]. However, it is noted that most of the studies have focused on sodium hydroxide (NH) and sodium silicate (NS) as the main activators and very few studies investigated the properties of 
AASF concrete. In addition, there is a dearth of systematic studies on the durability of AASF materials.

Recently, Gopalakrishnan and Chinnaraju [13] studied the sulphate resistance of silicateactivated slag/fly ash. They concluded that in sulphate environment AASF concrete with $40 \%$ fly ash performs well among all the mixes. Hu et al. [12] studied the effects of silicate modulus, alkali dosage, fly ash content and steam curing on compressive strength, pore structure and chloride transport properties of silicate-slag/fly ash mortars.

The use of sodium carbonate (NC) as an activator offers many attractive engineering and environmental benefits as it results in reduced alkalinity of the systems, lower cost and lower carbon footprint and better workability of the fresh paste compared with conventional activators such as NS and NH. So far, NC has been commonly used to activate slag alone while NC-activated slag/fly ash (NC-SF) binders have attracted less attention except for some recent work [14-19]. Most of the work on NC has been focusing on blending NC and other activators. For example Ishwarya et al. [20] studied the effect of sodium carbonate/sodium silicate activator on the rheology, geopolymerization and strength of fly ash/slag geopolymer pastes. They developed a mortar with more than $70 \mathrm{MPa}$. Ban et al. [21] found that the mechanical strength of sodium carbonate and sodium silicate activated slag /fly ash was comparable with that of the sodium hydroxide activated slag/fly ash.

More recently, detailed investigation into the role of NC [22], the effect of slag chemistry [23] in the activation of slag was conducted. However, these two studies focused on a single dosage of $\mathrm{NC}(8 \%)$. The effect of various activator doses $(4,6,8 \%)$ on the reaction products and strength was studied by Jin and Al-Tabbaa [24]. Among all these studies, only two dealt with the properties of sodium carbonate-activated slag concrete and a single study considered some durability aspects (what are these) of the concrete. More studies investigating the activation of slag and fly ash blends solely by NC are required.

The effect of $\mathrm{MgO}$ additive on the mechanical properties and volume stability of AAS systems has shown that the incorporation of $\mathrm{MgO}$ exhibited a great influence on these properties [2426]. These properties depend on the slag properties, activator type and dosage as well as the reactivity of $\mathrm{MgO}$. The effect of $\mathrm{MgO}$ reactivity on the strength and shrinkage of NS and NCS binders has been studied by Jin and co-workers [24,25]. They, for instance, investigated the effect of two different reactive MgOs on the compressive strength of NS-activated slag pastes. 
They found that, when high-reactive $\mathrm{MgO}\left(\mathrm{MgO}_{\mathrm{H}}\right)$ was used, the strength increased as the $\mathrm{MgO}$ content increased. When the medium reactive $\left(\mathrm{MgO}_{\mathrm{M}}\right)$ was used, the early strength slightly decreased as the $\mathrm{MgO}$ content increased, while at later ages (> 7 days) the addition of $2.5 \% \mathrm{MgO}_{\mathrm{H}}$ increased the strength but further increase in the $\mathrm{MgO}$ gave comparable strength to the sample with $0 \% \mathrm{MgO}$ [27]. Similar results were observed in NC-S pastes when both $\mathrm{MgO}_{\mathrm{H}}$ and $\mathrm{MgO}_{\mathrm{M}}$ were used. Fang et al. [28] studied the effect of the calcination temperature (800-950 ${ }^{\circ} \mathrm{C}$ ) on the $\mathrm{MgO}$ interaction with NS-activated slag system. They found that the increase in the $\mathrm{MgO}$ addition led to a reduction in the compressive strength and they reported that the higher the temperature was (i.e. the lower the reactivity), the less adverse the effect of $\mathrm{MgO}$.

Reactive $\mathrm{MgO}$ has shown promising results in the activation of slag and the compensation of shrinkage. This dual role can be beneficial in alkali activated systems because these systems depend on the activation by alkalis and meanwhile suffer high rates of drying shrinkage. It has been reported that the incorporation of $\mathrm{MgO}$ in AAS binders increased the strength and reduced the shrinkage, which is attributed to the increased formation of hydrotalcite (Ht). Very recently, $\mathrm{Pu}$ and Unluer [29] studied the durability of carbonated $\mathrm{MgO}$ concrete containing fly ash and ground granulated blast-furnace slag. They found that the concrete samples revealed a better performance over PC samples in sulphate attack and freeze-thaw cycling, which was associated with the stability of their phases under aggressive environments. They also showed that the incorporation of fly ash and slag improved the durability of concrete by enabling denser microstructures and formation of phases that were stable under the tested conditions. There are few studies on the role of $\mathrm{MgO}$ in alkali activated materials (AAMs) and further investigation on $\mathrm{MgO}$ modified corresponding systems, in particular NC-SF binders, is required.

The effect of superplasticisers (SPs) on alkaline cement paste, mortar and concrete behaviour and properties has not been very widely addressed in the literature. Moreover, the results reported by different authors are often contradictory, perhaps due to variations in conditions such as the nature of the material to be activated (slag, fly ash), the nature and concentration of the alkali activator, and the type and dosage of the admixture. Previous study showed that the workability of MgO-modified NC-SF pastes could be improved by using the lignosulphonatebased SP [17]. Therefore, this study will use this type of SP in the developed mixes to understand the role of this SP on the mechanical and durability properties of AASF concrete. 
Despite the remarkable progress in understanding the microstructure and properties of NC-SF materials, more insight is required to understand the properties of NC-SF concrete, particularly the durability of NC-SF concrete. This paper aims to investigate the mechanical and durability properties of MgO-modified NC-SF concrete mixtures.

\section{Materials and methods}

\subsection{Materials, mix design and sample preparation}

The slag used was supplied by Hanson cement, UK, and has basicity $\left(K_{b}=\frac{C a O+M g O}{\mathrm{SiO}_{2}+\mathrm{Al}_{2} \mathrm{O}_{3}}\right)$ and hydration modulus $\left(\mathrm{HM}=\frac{\mathrm{CaO}+\mathrm{MgO} \mathrm{Al}_{2} \mathrm{O}_{3}}{\mathrm{SiO}_{2}}\right)$ values of $\sim 1.0$ and $\sim 1.60$, respectively. The slag was mainly amorphous, with merwinite $\left(\mathrm{Ca}_{3} \mathrm{Mg}\left(\mathrm{SiO}_{4}\right)_{2}\right.$, Powder Diffraction File (PDF) \#35591) identified as the only crystalline phase present by XRD analysis (not presented here). The fly ash was obtained from Cemex, Rugby, UK and is classified to meet the requirements of the British standard for use with PC (BS 3892: Part 1). The MgO was obtained from Richard Baker Harrison, UK, and has a reactivity of $170 \mathrm{sec}$ according to the acetic acid test, which indicates medium reactivity according to the classification of Jin and Al-Tabbaa [30]. The chemical compositions of all materials are shown in Table 1. Sodium carbonate was supplied by Fisher scientific, UK as a powder and has the purity of $99 \%$. It was dissolved in the mix water until complete dissolution was reached. For control mixes, alkali activator of a blend of NS, NH and water was used to achieve a $\mathrm{Na}_{2} \mathrm{O}$ dosage of $5 \%$ and activator modulus (Ms) of 1.25 in the range (1.0-1.5) defined to be the optimal range for AAMs [31]. NS powder (wt. ratio: $\mathrm{SiO}_{2} / \mathrm{Na}_{2} \mathrm{O}=2$, technical grade) and $\mathrm{NH}$ pellets (technical grade) were supplied by Fisher Scientific. A superplasticiser (SP), based on modified lignosulphonates, was supplied by Sika under the brand name of Plastiment 180.

Table 1 Chemical composition and physical characteristics of the materials used (based on the suppliers' datasheets)

\begin{tabular}{lccc}
\hline Component (wt\%) & Slag & Fly Ash & MgO \\
\hline $\mathrm{CaO}$ & 39.24 & $6.8 \pm 3.6$ & 1.9 \\
\hline $\mathrm{SiO}_{2}$ & 36.79 & $49.3 \pm 6.2$ & 0.9 \\
\hline $\mathrm{Al}_{2} \mathrm{O}_{3}$ & & & 0.1 \\
\end{tabular}




\begin{tabular}{lccc}
\hline $\mathrm{Fe}_{2} \mathrm{O}_{3}$ & 0.42 & $9.7 \pm 1.3$ & 0.8 \\
\hline $\mathrm{MgO}$ & 8.10 & $1.1 \pm 0.2$ & 93.5 \\
\hline $\mathrm{SO}_{3}$ & 1.03 & $3.3 \pm 1.3$ & - \\
\hline $\mathrm{K}_{2} \mathrm{O}$ & & & - \\
\hline $\mathrm{Na}_{2} \mathrm{O}$ & 0.63 & $3.5 \pm 0.3$ & - \\
\hline $\mathrm{SSA}\left(\mathrm{m}^{2} / \mathrm{kg}\right)$ & 0.37 & $1.2 \pm 0.1$ & 9000
\end{tabular}

Two series of mixes were designed as shown in Table 2. The first series (Series I) contains no SP and was designed to study the effect of slag/fly ash ratio (100:0 and 75:25) and the incorporation of reactive $\mathrm{MgO}$ (10\% in replacement of slag/fly ash). The second series (Series II) was designed to study the influence of adding $1 \%$ SP (by weight of the total binder) on the properties of the mixes in series I. In all mixes the binder:water:sand:gravel ratio was kept constant at 1:0.4:1.5:3 and the NC dosage was $10 \%$ by weight of the binder. A control concrete mix, using sodium silicate (NS) and sodium hydroxide $(\mathrm{NH})$ as the activator (with $5 \% \mathrm{Na}_{2} \mathrm{O}$ content by weight of slag and a modulus of 1.25), was designed in order to compare its durability performance with the designed NC-activated mixes.

Table 2 Mix details of the AASF binder investigated

\begin{tabular}{|c|c|c|c|c|c|c|c|}
\hline \multirow{2}{*}{ Series } & \multirow{2}{*}{ Mix ID } & \multicolumn{3}{|c|}{ Solid mix constituents $(\%)$} & \multirow{2}{*}{ Activator* } & \multirow{2}{*}{$\begin{array}{c}\text { SP } \\
(\%)^{*}\end{array}$} & \multirow{2}{*}{$\mathbf{w} / \mathbf{b}$} \\
\hline & & Slag & Fly ash & MgO & & & \\
\hline Control & control & 100 & - & - & $\begin{array}{c}\mathrm{NS}+\mathrm{NH}(5 \% \\
\mathrm{Na}_{2} \mathrm{O}, 1.25 \\
\mathrm{Ms})\end{array}$ & - & \multirow{7}{*}{0.4} \\
\hline \multirow{3}{*}{$\mathbf{I}$} & A10 & 100 & - & - & \multirow{3}{*}{$10 \% \mathrm{NC}$} & \multirow{3}{*}{ - } & \\
\hline & B10 & 75 & 25 & - & & & \\
\hline & B10M10 & 67.5 & 22.5 & 10 & & & \\
\hline \multirow{3}{*}{ II } & A10-SP & 100 & - & - & \multirow{3}{*}{$10 \% \mathrm{NC}$} & \multirow{3}{*}{1} & \\
\hline & B10-SP & 75 & 25 & - & & & \\
\hline & B10M10-SP & 67.5 & 22.5 & 10 & & & \\
\hline
\end{tabular}

* as an additive of the solid constituents 
Table 3 Details of designed AASF concrete mix proportions in $\mathrm{kg} / \mathrm{m}^{3}$.

\begin{tabular}{|c|c|c|c|c|c|c|c|c|c|c|c|}
\hline Series & Mix ID & Slag & $\begin{array}{l}\text { Fly } \\
\text { ash }\end{array}$ & MgO & sand & gravel & $\mathrm{NC}$ & NS & NH & $\mathbf{S P}$ & water \\
\hline$\overline{\text { Control }}$ & Control & 370 & 0 & 0 & \multirow{7}{*}{555} & \multirow{7}{*}{1110} & 0 & 22.8 & 9 & 0 & \multirow{7}{*}{148} \\
\hline \multirow{3}{*}{ I } & A10 & 370 & 0 & 0 & & & \multirow{6}{*}{37} & \multirow{6}{*}{0} & \multirow{6}{*}{0} & \multirow{3}{*}{0} & \\
\hline & B10 & 277.5 & 92.5 & 0 & & & & & & & \\
\hline & B10M10 & 249.8 & 83.2 & 37 & & & & & & & \\
\hline \multirow{3}{*}{ II } & A10-SP & 370 & 0 & 0 & & & & & & \multirow{3}{*}{3.7} & \\
\hline & B10-SP & 277.5 & 92.5 & 0 & & & & & & & \\
\hline & B10M10-SP & 249.8 & 83.2 & 37 & & & & & & & \\
\hline
\end{tabular}

Concrete was mixed by various concrete mixers depending on the volume of the batch. Following five minutes of mixing of the dry ingredients, alkali solution was added and then mixed for a further five minutes. In the case of using the plasticiser, it was added three minutes after adding the alkali solution and then mixed for a further two minutes.

Concrete was cast into $100 \mathrm{~mm}$ steel cubes for compressive strength and carbonation resistance tests, $\varnothing 100 * 200 \mathrm{~mm}$ cylindrical steel moulds for indirect tensile strength test and $\varnothing 50 * 100$ $\mathrm{mm}$ cylindrical plastic moulds for the various durability tests. For each mix, the specimen was compacted on a vibrating table for approximately 1 minute to remove air bubbles. The samples were demoulded after two days of curing in ambient conditions and then cured in plastic wraps at temperatures of $20 \pm 1{ }^{\circ} \mathrm{C}$ and $\sim 99 \%$ relative humidity (RH) until the designated testing age.

\subsection{Testing methods}

\subsubsection{Strength tests}

Compressive and tensile splitting strength of concrete were evaluated in accordance with BS EN 12390-3 [32] and BS EN 12390-6 [33], respectively with a $250 \mathrm{kN}$-capacity Controls Testing Advantest 9 frame. Triplicate cubes were tested at ages of 3, 7, 28, 56 and 90 days and the average strength was reported.

\subsubsection{Water absorption test}

The water absorption of NC-SF concrete was measured as per BS 1881-122 [34] with sample size of $\varnothing 50 * 100 \mathrm{~mm}$. The samples were dried in an oven at a temperature of $105{ }^{\circ} \mathrm{C}$ for 72 hours after 24 days of curing, followed by cooling in an airtight vessel for 24 hours to cool. 
The samples were then weighted and immersed in water tank for 30 minutes with its longitudinal axis horizontal and at a depth such that there was $25 \mathrm{~mm}$ of water over the top of the specimens. The measured absorption of each specimen was calculated as the increase in mass by the mass of the dry specimen.

\subsubsection{Durability tests}

In order to study the performance of the concrete samples in aggressive environments, all samples from series I (A10, B10 and B10M10) in addition to the control sample and B10-SP from series II are selected. The durability performance of these concrete mixes was evaluated by acid, sulphate, carbonation and elevated-temperature resistance tests as shown below.

\section{Acid and sulphate resistance test}

After 28 days of curing, the cylindrical concrete samples were transfer to $9 \mathrm{~L}$ containers with the following solutions:

- $1 \%$ hydrochloric acid $(\mathrm{HCl})$ solution at $\mathrm{pH}$ of $\sim 0.85-1.0$

- $5 \%$ sodium sulphate $\left(\mathrm{Na}_{2} \mathrm{SO}_{4}\right)$ solution at $\mathrm{pH}$ of $\sim 6-8$

- $5 \%$ magnesium sulphate $\left(\mathrm{MgSO}_{4}\right)$ solution at $\mathrm{pH}$ of $\sim 6-8$

The cylinders were totally immersed in the solutions, which were renewed monthly up to 3 months. Each set of samples (three replicates) was placed in a separate container to eliminate cross contamination. When the solutions were renewed, samples were removed from the containers, brushed with a soft nylon brush to remove loose surface material. Prior to immersion in the renewed solution, the samples were dried by paper tissue, then visual inspected, photographed and weighted. The change in weight of samples was compared to that before the chemical attack and was calculated as follows:

$\mathrm{L}_{\mathrm{t}}=\left(\left(\mathrm{M}_{0}-\mathrm{M}_{\mathrm{t}}\right) / \mathrm{M}_{0}\right) * 100 \% \quad$ Eq. (1)

where, $\mathrm{L}_{\mathrm{t}}$ is the loss in weight of testing age, $\mathrm{M}_{0}$ is the initial weight, measured on the day before chemical attack started (in grams) and $\mathrm{M}_{\mathrm{t}}$ is the weight of the sample measured at the designated age (in grams). After 6 months of immersion, samples were visual inspected, weighed and tested for compressive strength. 


\section{Carbonation resistance test}

The carbonation resistance test was carried out in accordance to BS 1881-210 [35]. Two cubic specimens of $100 \mathrm{~mm}$ are prepared and sealed cured for 28 days followed by conditioning the specimens in a laboratory air environment (at $20 \pm 2{ }^{\circ} \mathrm{C}$ ) and $50-65 \% \mathrm{RH}$ ) for 14 days. The top, bottom and two opposite side faces were then sealed using paraffin wax in three equal layers, leaving the wax to set on the concrete between each application. Thereafter, the cubes were placed in the $\mathrm{CO}_{2}$ incubator, positioned in a way that permits $\mathrm{CO}_{2}$ to circulate freely around the two faces that are to be carbonated.

The carbonation conditions were set at a $\mathrm{CO}_{2}$ level of $4.0 \pm 0.5 \%$, temperature of $20 \pm 2{ }^{\circ} \mathrm{C}$ and $\mathrm{RH}$ of $55 \pm 5 \%$ for a period of 70 days. Then the cubes were split in half perpendicular to the exposed faces and the depth of carbonation was measured. The carbonation depth on the surface of the cube was measured by spraying $1 \%$ phenolphthalein solution according to the standard EN 13295:2004 [36]. After spraying, the noncarbonated area, where the $\mathrm{pH}$ is above a value in the range of 8.4 to 9.8 , would become purple. The carbonation depth was measured at five points on each exposed face and mean depth of carbonation was then calculated. Additional two specimens for each mixture were used to measure the compressive strength after exposure and compared with non-carbonated specimens at the same curing age.

\section{Elevated-temperature resistance test}

Three cylindrical concrete specimens were used to examine their resistance to elevated temperature exposure. After sealed curing for 28 days, specimens were subjected to temperatures of $500{ }^{\circ} \mathrm{C}$ or $800{ }^{\circ} \mathrm{C}$ at an incremental rate of $4{ }^{\circ} \mathrm{C}$ per minute from room temperature using a muffle furnace. The temperature was sustained at the targeted temperature for $1 \mathrm{~h}$ before the specimens were allowed to cool naturally to room temperature inside the furnace and were then weighted, photographed and subjected to compressive strength testing to assess the residual strength. The elevated temperature exposure cycle is illustrated in Figure 1, which represents the lower bound strength values compared with the stressed residual test [37]. The results were compared with the normal cured specimens at the age of 28 days. 


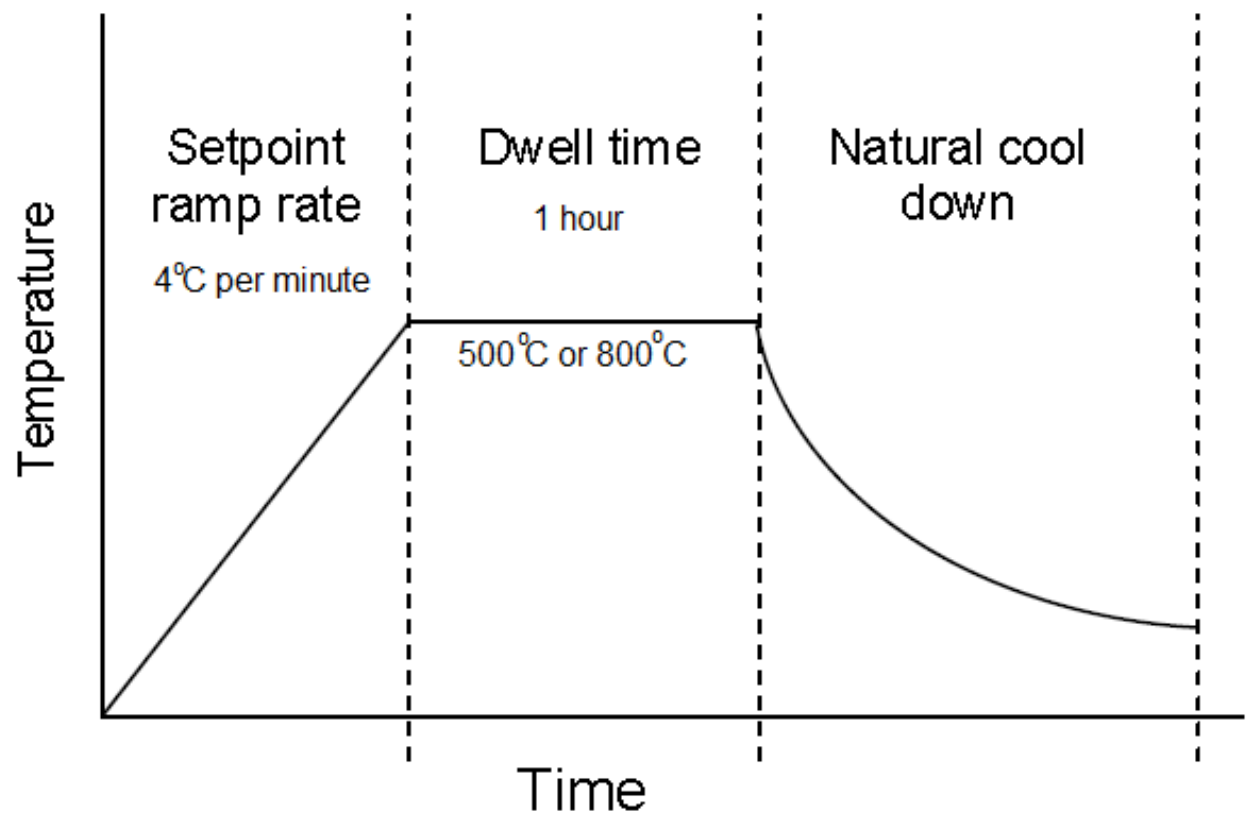

Figure 1 Elevated-temperature testing procedure.

\subsubsection{Microstructural tests}

In order to elucidate the microstructural change of the cement paste before and after durability tests, various analytical techniques were utilised including Powder X-Ray diffraction (PXRD), Thermogravimetric analysis (TGA) and Attenuated Total Reflectance Fourier Transform Infrared spectroscopy (ATR-FTIR). Immediately after the compressive strength test at 28 days and specific times of exposure to the various durability tests, selected samples from the surface of the specimen for microstructural analyses were immersed in acetone for three days in order to stop any further hydration. The separation between the aggregates and the paste was carefully conducted. Then the samples were filtered to remove the acetone followed by vacuum drying in a desiccator. The samples were then put in the oven at $60^{\circ} \mathrm{C}$ for $24 \mathrm{hrs}$. Thereafter, part of the samples was crushed and ground in the agate mortar until passing the $75 \mu \mathrm{m}$ sieve. The powders obtained were sealed in plastic vials for further analyses.

PXRD was performed using the Siemens D500 X-ray diffractometer with a CuK $\alpha$ source operating at $40 \mathrm{kV}$ and $40 \mathrm{~mA}$, emitting radiation at a wavelength of $1.5405 \AA$. The scanning regions were between $2 \theta$ values of 15 to $60^{\circ}$, at a resolution of $0.02^{\circ} /$ step. TGA was conducted using $20 \pm 2 \mathrm{mg}$ powder under static air in an open alumina crucible heated at $10{ }^{\circ} \mathrm{C} / \mathrm{min}$ over the range of $40-1000^{\circ} \mathrm{C}$ on a Perkin Elmer STA6000 machine. ATR-FTIR spectra of the samples were taken using Perkin Elmer FTIR Spectrometer Spectrum 100 Optica. Spectra were collected in a transmittance mode from 4000 to $600 \mathrm{~cm}^{-1}$ at a resolution of $1 \mathrm{~cm}^{-1}$. 


\section{Results and Discussions}

\subsection{Mechanical strengths}

Figure 2 presents the compressive strength development of the concrete samples in Table 2 without SP (solid black lines, Series I) and with SP (dashed red lines, Series II). It is apparent that all mixes in this study displayed a higher compressive strength than the control mix after 28 days of sealed curing. A progressive development of strength was noticed for all the concrete mixes up to 90 days. The compressive strength sharply increased from 3 to 7 days and then gradually increased up to 28 days. Between 28 days and 90 days, the compressive strength increased at a slower rate.

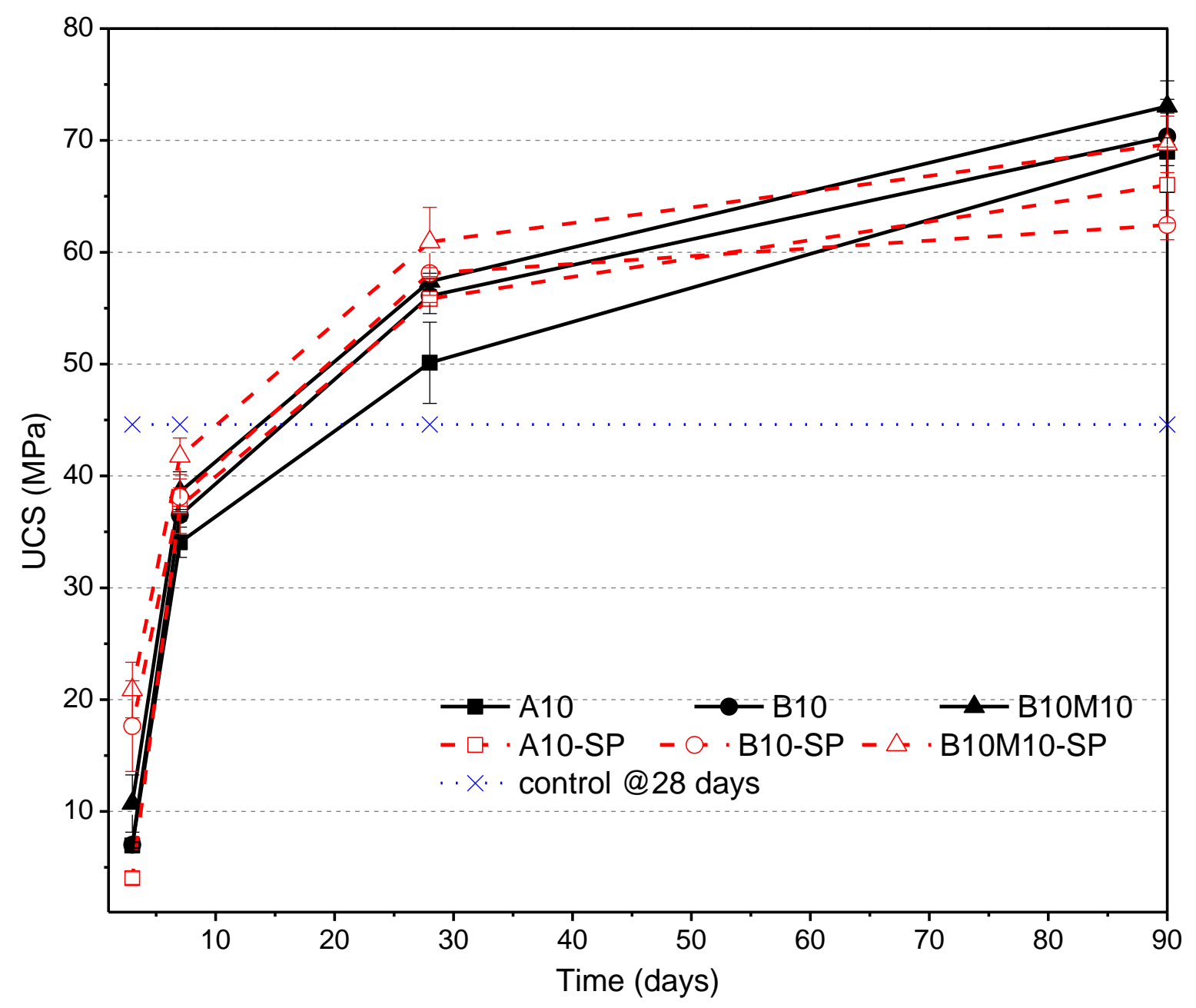

Figure 2 Compressive strength development of Series I and II concrete mixes. 
At 3 days, the inclusion of fly ash (Mix B10) did not change the strength, while the incorporation of reactive $\mathrm{MgO}$ (Mix B10M10) slightly increased it, when no SP was added. The addition of SP decreased the early strength of neat slag sample (comparing A10 and A10SP). However, sample B10-SP and B10M10-SP, surprisingly, exhibited higher early strength than B10 and B10M10, respectively. The compressive strength after 28 days of all samples was between 50 and $60 \mathrm{MPa}$ which is sufficient for normal concrete applications. These results are in agreement with other studies on different AAM concrete [2,38-42]. Yazdi et al. found that replacing fly ash with slag by up to $50 \%$ results in a very pronounced increase in the compressive strength, particularly at early ages [43]. The 28-day strength values indicate that the strength increased with the inclusion of fly ash and reactive $\mathrm{MgO}$ and further increased when SP was added. At 90 days, the compressive strength narrowly ranged between $\sim 63 \mathrm{MPa}$ and $73 \mathrm{MPa}$ for B10-SP and B10M10, respectively. Again, the inclusion of fly ash (B10) and reactive $\mathrm{MgO}$ (B10M10) increased the 90-day strength, compared to A10. However, unlike earlier ages, the addition of SP led to reduction in the compressive strength at 90 days.

The tensile strengths of concrete samples at 3, 7, 28 and 90 days are plotted in Figure 3. The splitting tensile strength shows a similar trend to compressive strength, with progressive development of the split tensile strength with time for all mixtures. At early ages ( $\leq 7$ days), the tensile strength increased with the addition of reactive $\mathrm{MgO}$ and SP. For example, sample B10M10 gained 52\% higher 3-day tensile strength than B10. However, at later ages ( $\geq 28$ days), there was a marginal difference between all mixes. The 28-day tensile strength values, for instance, varied between 3.5 and 4.0 MPa while the 90-day tensile strength values varied from 4.5 to $\sim 5.0 \mathrm{MPa}$. These values are consistent with what have been reported by other researchers on AASF concrete [44]. 


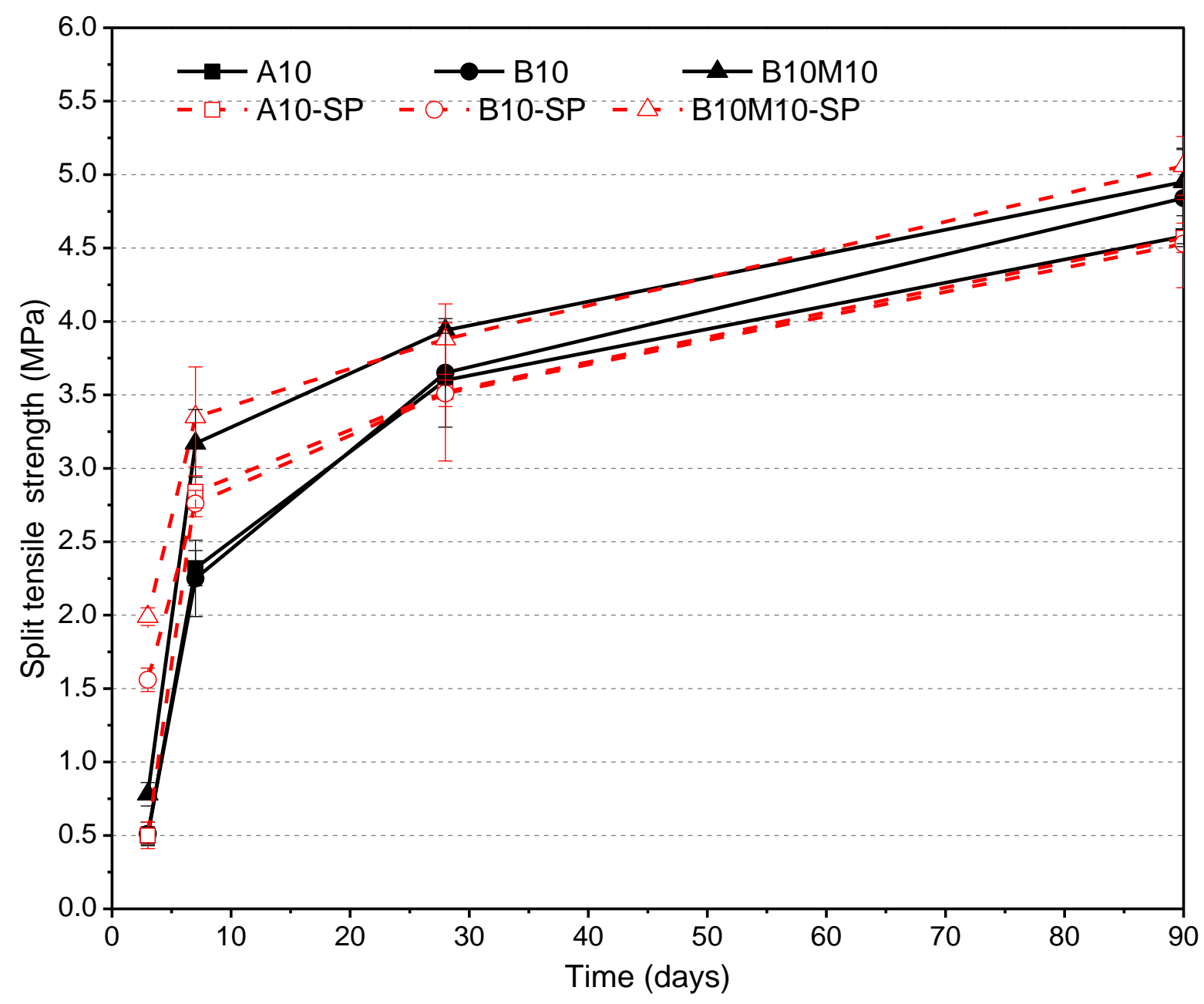

Figure 3 Splitting tensile strength development of Series I and II concrete mixes

\subsection{Water absorption}

Figure 4 presents the water absorption values of all the concrete samples, ranging between 3.5 and 5\%, which is in agreement with the literature [45]. Olivia et al. [46] reported that the water absorption values for normal strength PC concrete are usually between 3 and 5\%. It was found that the water absorption values of all samples, except B10M10, were higher than the control sample When no SP was added, the results suggest that the water absorption increased with the inclusion of fly ash while it decreased when $10 \%$ reactive $\mathrm{MgO}$ replaced the slag and fly ash. The increase in paste volume due to the lower specific gravity of fly ash and the porous nature of fly ash may contribute to the increase in the capillary pore volume and water absorption [47]. The reduction in the water absorption due to the inclusion of reactive $\mathrm{MgO}$ could be explained as a result of the reduced porosity, which corroborates with the increase compressive strength by adding reactive $\mathrm{MgO}$ (see Figs. $2 \& 3$ ). The addition of SP led to higher water 
absorption values, with the exception for B10 mix. The effect of these factors on the water absorption cannot be well established according to the measurements presented in Figure 4, so detailed investigation is required. In addition, high temperatures were used during preconditioning of the specimens, in particular $105^{\circ} \mathrm{C}$ and this alter the pore structure of alkaliactivated material and thus give biased results as stated by Zhang et al. [48]

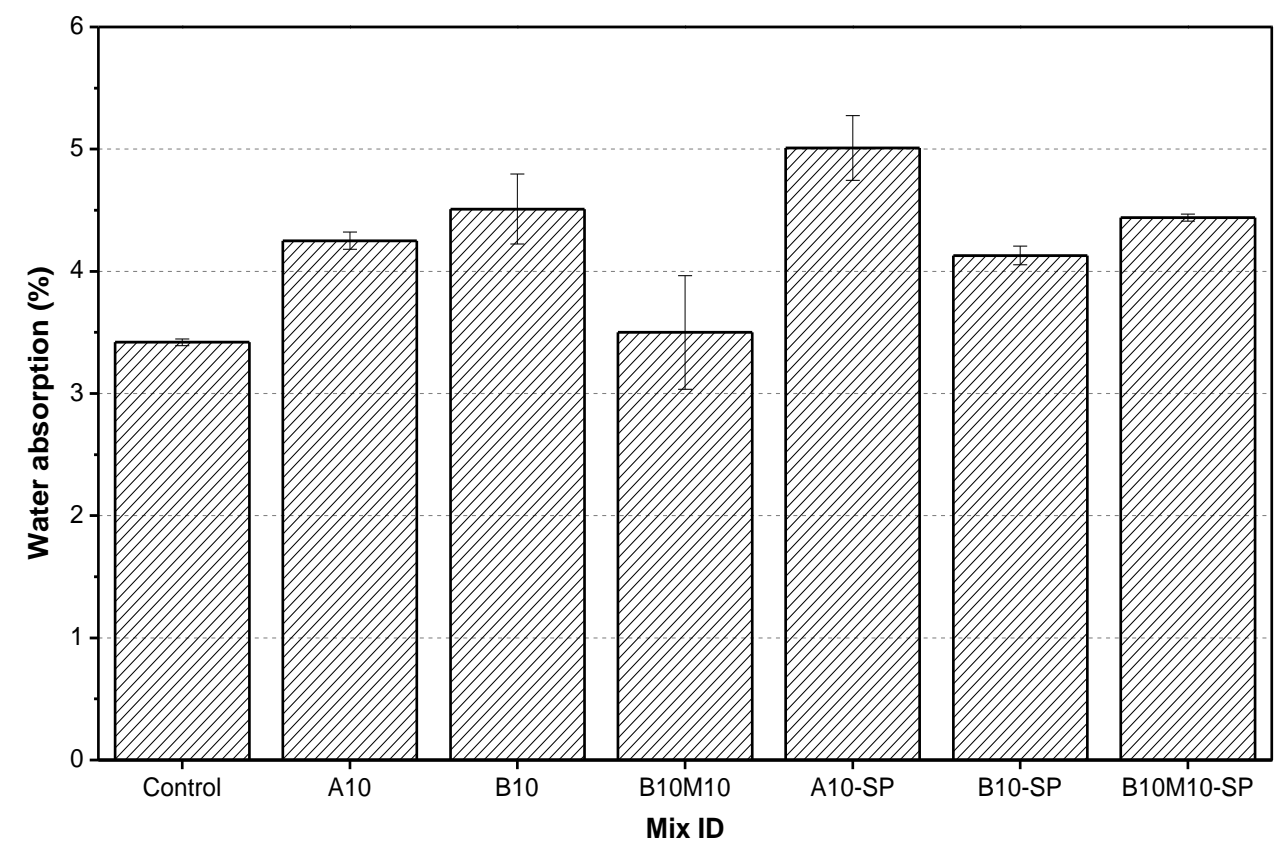

Figure 4 Water absorption values of the concrete mixes after 28 days of curing.

\subsection{Sulphate resistance}

The concrete samples of mixes A10, B10, B10-SP and B10M10 were immersed in $\mathrm{Na}_{2} \mathrm{SO}_{4}$ and $\mathrm{MgSO}_{4}$ solutions for six months to assess their sulphate resistance. The main criteria of comparison between mixes were based on visual inspection and changes in compressive strength. However, further analysis via PXRD and TGA were performed on selected samples to elucidate the microstructural changes upon exposure to sulphate environments. The samples immersed in $\mathrm{Na}_{2} \mathrm{SO}_{4}$ or $\mathrm{MgSO}_{4}$ solutions were assessed visually for any deterioration after 6 months as can be seen in Table 4. None of the samples immersed in $\mathrm{Na}_{2} \mathrm{SO}_{4}$ solution show any signs of surface erosion, cracking or spalling after 6 months. In contrast, physical deterioration and some signs of surface erosion was observed for the control sample immersed in the $\mathrm{MgSO}_{4}$ solution after 6 months while all other samples showed no change in appearance In addition, no significant changes were observed in the weight of the samples after immersion in both solutions (not shown). 
Table 4 Visual examination of concrete samples after immersion in sulphate solutions for 6 months.

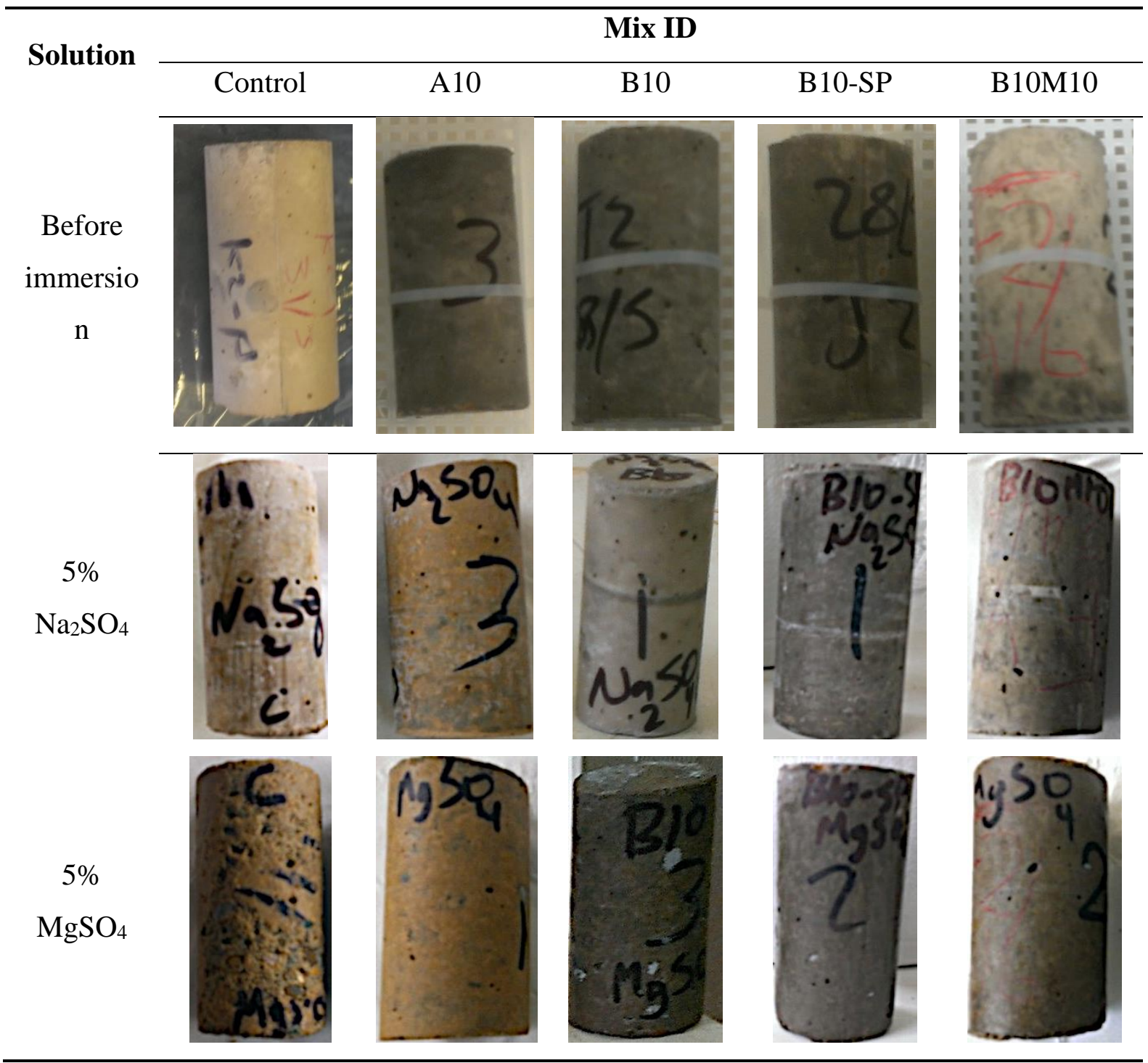

Figure 5 compares the compressive strength of the concrete specimens before and after the exposure to both sulphate solutions. After immersion in $\mathrm{Na}_{2} \mathrm{SO}_{4}$, all samples exhibited a slight increment in the compressive strength, except the control and mix A10, which experienced a marginal decrease in the strength. The data suggest that the inclusion of fly ash, $\mathrm{MgO}$ and SP was beneficial to the resistance of $\mathrm{Na}_{2} \mathrm{SO}_{4}$ attack.

On the other hand, the strength of the control sample significantly decreased by $28 \%$ after immersion in the $\mathrm{MgSO}_{4}$ solution while A10 sample decreased marginally by $7 \%$. In contrast, the strength of samples with the inclusion of fly ash, reactive $\mathrm{MgO}$ and SP slightly increased 
after $\mathrm{MgSO}_{4}$ immersion. The results of the control sample in this study are consistent with those reported in $[13,49]$, which found that the exposure to $\mathrm{MgSO}_{4}$ caused more deterioration than to $\mathrm{Na}_{2} \mathrm{SO}_{4}$. Therefore, they concluded that the process of sulphate attack on NS-activated slag/fly ash binders strongly depends on the cation accompanying the sulphate. This study showed that NC-SF concrete exhibited high resistance to both magnesium and sodium sulphate exposures and it outperformed the AAS [50] and AAFA concrete [51]. The results suggest the benefits of using $\mathrm{NC}$ as the activator, combining slag and fly ash and adding reactive $\mathrm{MgO}$ in the binder in terms of improving the sulphate resistance of AAS concrete.

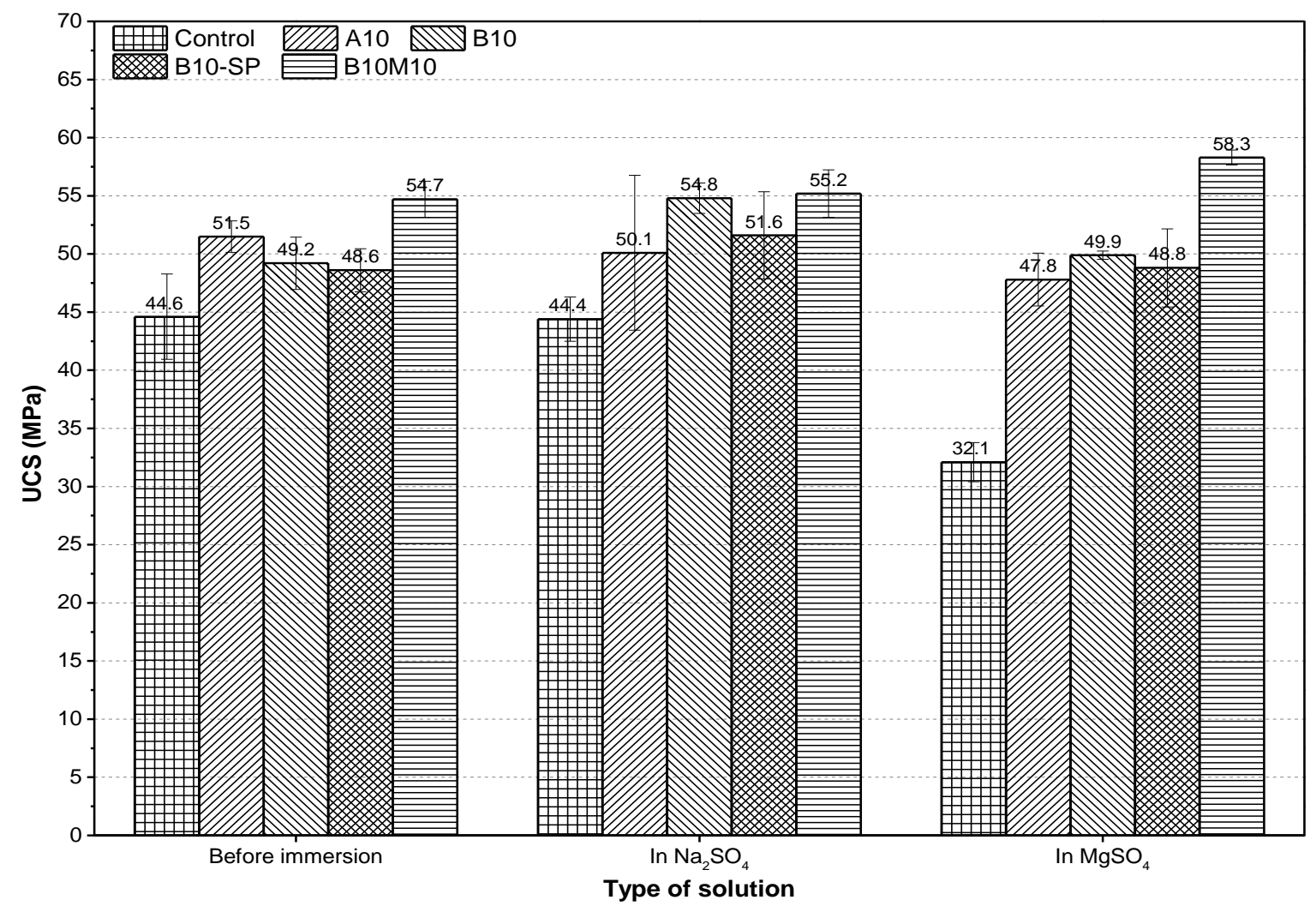

Figure 5 Compressive strength change of mixes A10, B10, B10M10 and B10-SP before and after immersion in sulphate solutions for six months.

The PXRD patterns of mixes B10 and B10M10 before and after immersion in sulphate solutions are shown in Figure 6. The main phases that were detected before immersion for both mixes were quartz (SiO2 PDF\# 01-079-1910), gaylussite $\left(\mathrm{Na}_{2} \mathrm{Ca}\left(\mathrm{CO}_{3}\right)_{2} \cdot 5 \mathrm{H}_{2} \mathrm{O}\right.$, PDF\# 00-0120255), vaterite $\left(\mathrm{CaCO}_{3} \mathrm{PDF} \#\right.$ 01-075-9356), aragonite $\left(\mathrm{CaCO}_{3} \mathrm{PDF} \#\right.$ 01-076-0606), calcite $\left(\mathrm{CaCO}_{3}\right.$ PDF\# 01-071-3699), hydrotalcite $\left(\mathrm{Mg}_{6} \mathrm{Al}_{2}\left(\mathrm{CO}_{3}\right)(\mathrm{OH})_{16} .4\left(\mathrm{H}_{2} \mathrm{O}\right)\right)$-like phases $(\mathrm{Ht}$, PDF\# 00-041-1428) and the poorly crystalline C-(A)-S-H gel (PDF\# 00-022-0600). These are similar to the main phases detected in paste samples discussed in $[14,19]$. 


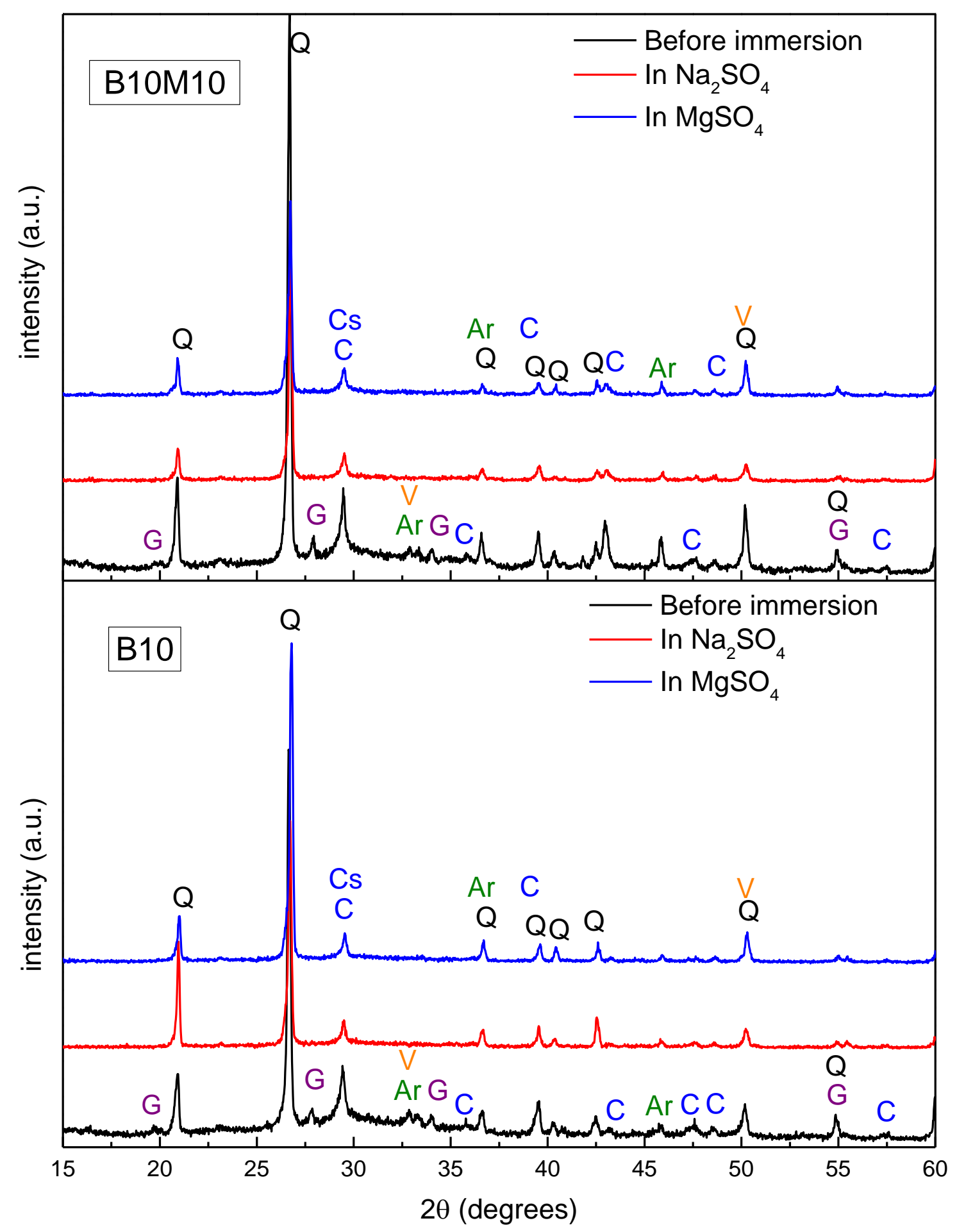

Figure 6 PXRD patterns of mix B10 (Bottom) and B10M10 (Top) before and after immersion in sulphate solutions for six months, where Ar: Argonite; C: Calcite; Cs: C-A-S-

H; G: gaylussite; Ht: Hydrotalcite-like phases; Mg: MgO; Q: Quartz; V: Vaterite. 
After immersion in both solutions, the main changes in the diffractograms of B10 and B10M10 took place in the transformation of gaylussite, vaterite and aragonite into more stable phases (i.e., calcite). The peak of the C-(A)-S-H gel did not change after immersion indicating that the decalcification or decomposition of this phase is unlikely to have taken place. In addition, unlike in silicate-activated systems, no gypsum was detected in any of the samples after exposure to sulphates.

The thermogravimetric analysis (TGA) and differential thermogravimetric (DTG) curves of concrete samples before and after immersion in the sulphate solutions are presented in Figure 7Error! Reference source not found.. Detectable peaks occurred at various temperatures were marked on the graph. The curves of the concrete samples before immersion in the solutions showed typical patterns of those observed in NC-SF paste [14]. The unexposed samples had four main peaks: (i) a peak positioned at $\sim 120{ }^{\circ} \mathrm{C}$ corresponds to the dehydration of the C-A$\mathrm{S}$-H gel; (ii) a peak centred at $\sim 365{ }^{\circ} \mathrm{C}$ is assigned to the dihydroxylation of $\mathrm{Ht}$; (iii) a peak at $\sim 480{ }^{\circ} \mathrm{C}$ refers to the decomposition of poorly crystalline calcium carbonate phases such as vaterite and aragonite; and (iv) a peak located at $\sim 700{ }^{\circ} \mathrm{C}$ corresponds to the decomposition of calcite.

The main differences between the samples were in the middle peaks. B10M10 displayed a higher peak of $\mathrm{Ht}$ and lower peaks of the poorly crystalline calcium carbonate phases, which could be due to the $\mathrm{CO}_{2}$ uptake for the formation of $\mathrm{Ht}$, thereby decreasing the availability of $\mathrm{CO}_{2}$ to form poorly crystalline $\mathrm{CaCO}_{3}$. After immersion in $\mathrm{Na}_{2} \mathrm{SO}_{4}$ solution, the DTG data show that the first peak shifted to a lower temperature and became sharper and more intense, particularly in samples B10M10. This could be due to the decomposition of the small amount of gypsum or the partially decalcified C-A-S-H. The middle peaks almost disappeared indicating the transformation of the poorly crystalline phases to more crystalined phases. This is consistent with the findings of PXRD. The DTG data of the samples after immersion in $\mathrm{MgSO}_{4}$ solution resemble those of the samples after immersion in $\mathrm{Na}_{2} \mathrm{SO}_{4}$. However, $\mathrm{Ht}$ is still observable, particularly for B10M10. The TGA results indicate that B10M10 samples has higher weight loss than B10 samples in all environments. 


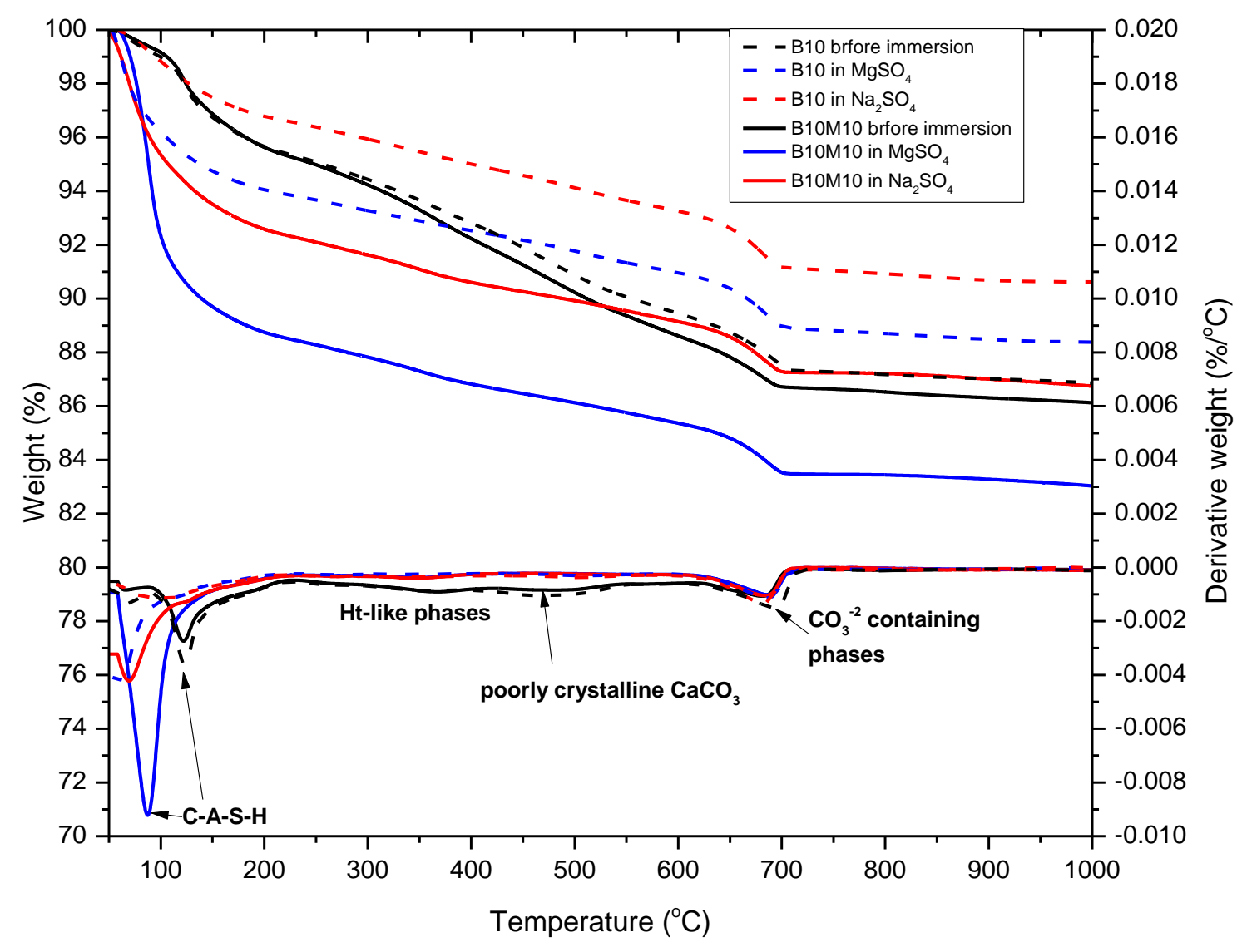

Figure 7 TGA and DTG curves of mixes B10 and B10M10 before and after immersion in sulphate solutions for six months.

\subsection{Acid resistance}

The visual examination of samples exposed to the $\mathrm{HCl}$ solution demonstrated that some changes in appearance occurred as can be seen in Table 5. Softening of the surface cover and insignificant lightening of the colour could be noticed in all samples. After crushing the samples, the cross section of the samples indicated the presence of two distinctive areas. The green colouration corresponding to the unexposed area and the beige colouration relates to the corroded depth when compared to untreated samples shown in Table 5, which showed no indication of colour change. From these distinctive areas, the depth of penetration was measured and found to range between 2.0 and $7.5 \mathrm{~mm}$ (three replicates). The data suggest that the addition of fly ash increased the penetration depth while the addition of reactive $\mathrm{MgO}$ notably decreased the acid ingress, which agreed with the water absorption values as discussed in Section 3.2. The introduction of SP hardly changed penetration depth. 
Table 5 Visual examination of concrete samples after immersion in acid solution for 6 months.

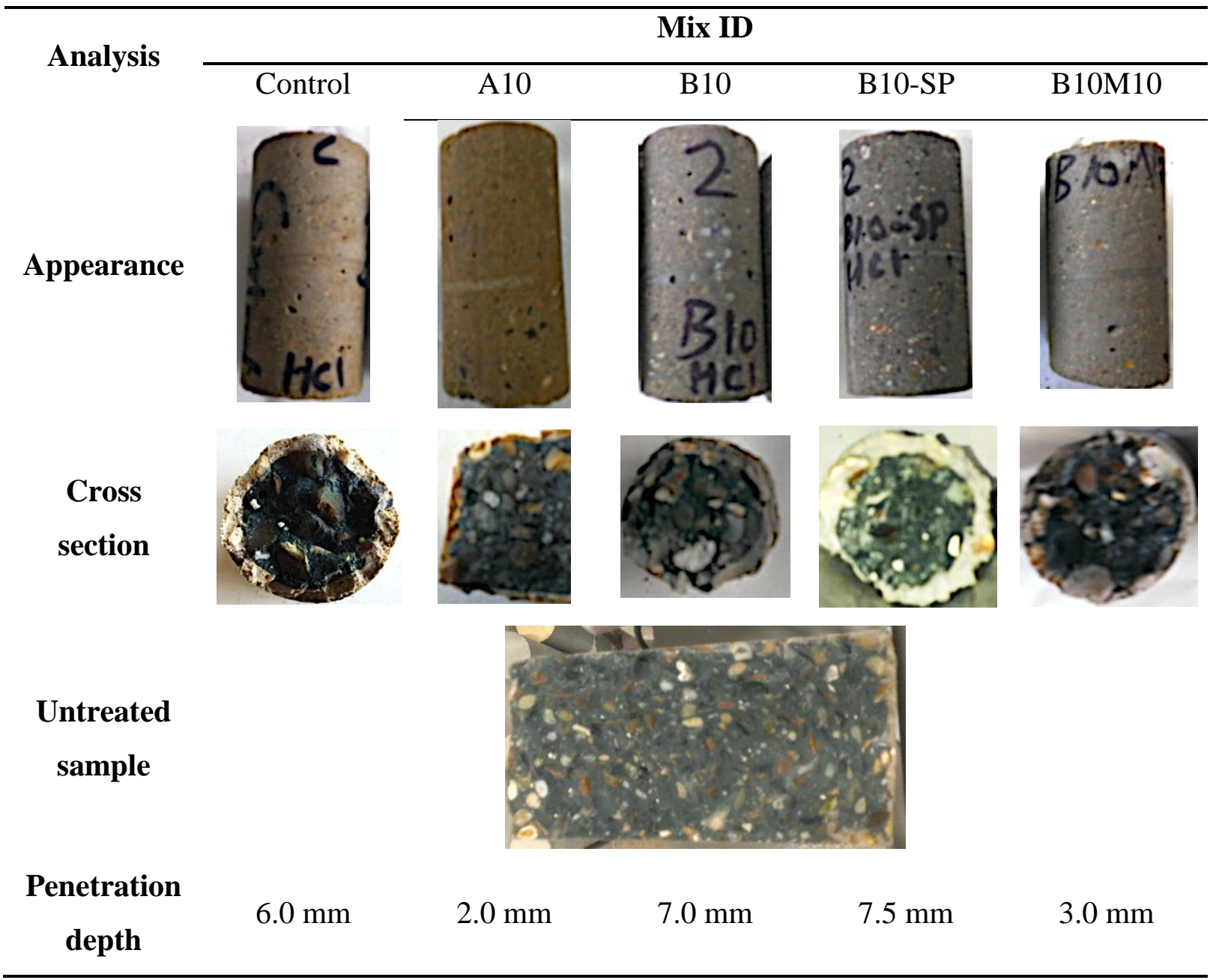

Figure 8 shows the loss in the strength and weight after the immersion of specimens in $\mathrm{HCl}$ solution for six months. The highest loss in strength $(\sim 67 \%)$ was observed for the control sample. This indicates that all samples outperformed the control sample after immersion in $\mathrm{HCl}$ solution, implying that the alkaline activator has strong influence on the resistance to acid attack. Sample A10 lost $27 \%$ of its initial strength after the exposure to $\mathrm{HCl}$ solution. The inclusion of fly ash (B10) doubled the loss of the strength compared to A10, while B10M10 lost only $23.12 \%$ of its initial strength, indicating that the addition of reactive $\mathrm{MgO}$ enhances the acid resistance of NC-SF concrete significantly. Similar to the penetration depth results, the addition of the SP had negligible effect on the strength loss. The weight loss of all samples did not exceed 5\%, with A10 exhibiting the lowest weight loss (2.29\%) and B10-SP the greatest weight loss $(4.59 \%)$. This implies that the loss of compressive strength is a more instrumental measure of performance than weight loss. 


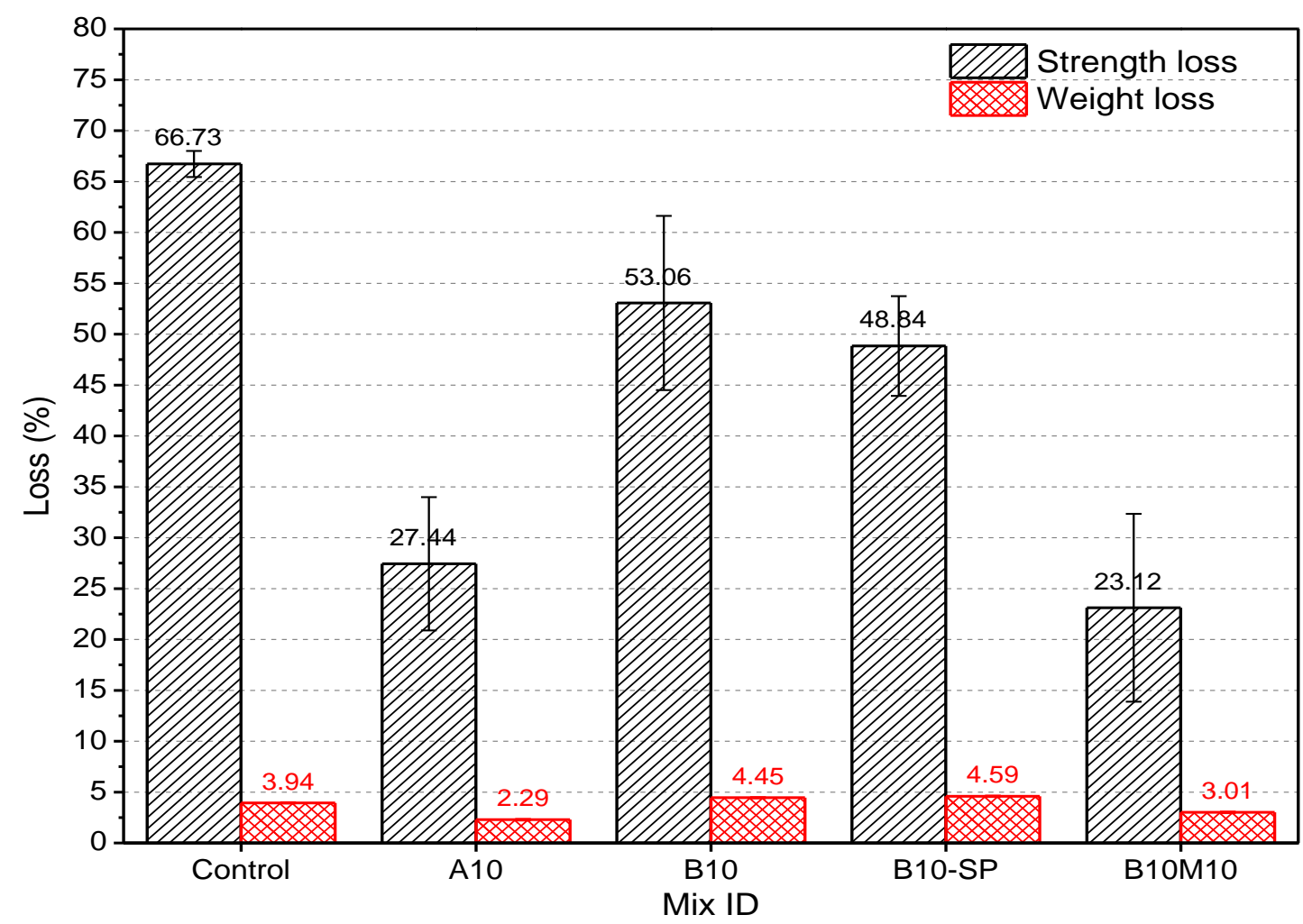

Figure 8 Loss in strength and weight of mixes A10, B10, B10M10 and B10-SP after immersion in $\mathrm{HCl}$ solution for six months.

Figure 9 shows the PXRD patterns of all samples after the exposure to acid attack for six months. The main phases detected were aragonite, calcite, C-S-H, Ht as well as unreacted phases such as quartz and $\mathrm{MgO}$. Compared to the PXRD patterns of the samples before exposure, the peaks corresponding to gaylussite and the poorly crystalline $\mathrm{CaCO}_{3}$ polymorphs (aragonite and vaterite) almost disappeared. This indicates that these phases are unstable and transform into more stable phases as curing time proceeds. The transformation of these phases, therefore, has no relation with the exposure to $\mathrm{HCl}[14,19]$.

After long term acid attack, the degradation of the C-(A)-S-H type gel and the formation of chlorides would be expected as confirmed by the strength and weight loss. However, the PXRD diffractograms of all samples indicated that there are no discernible changes in the crystalline phases due to the exposure to $\mathrm{HCl}$ solution; however, in sample B10 a new phase, sodium chloride $(\mathrm{NaCl})$, can be detected. Moreover, a reduction in the intensity of the amorphous hump associated with disordered C-A-S-H type gels was observed in all samples, suggesting partial dissolution of the main binding phase in the material during exposure to $\mathrm{HCl}$. This, in turn, led to the strength loss. It was difficult, in this study, to draw a full conclusion regarding the structural changes upon the exposure to $\mathrm{HCl}$ because the scanned samples were collected and 
mixed using the centred core (intact regions) and the corroded layer (exposed region) from each sample. The overlapping of the peaks from various phases also makes it difficult to identify new phases with confidence.

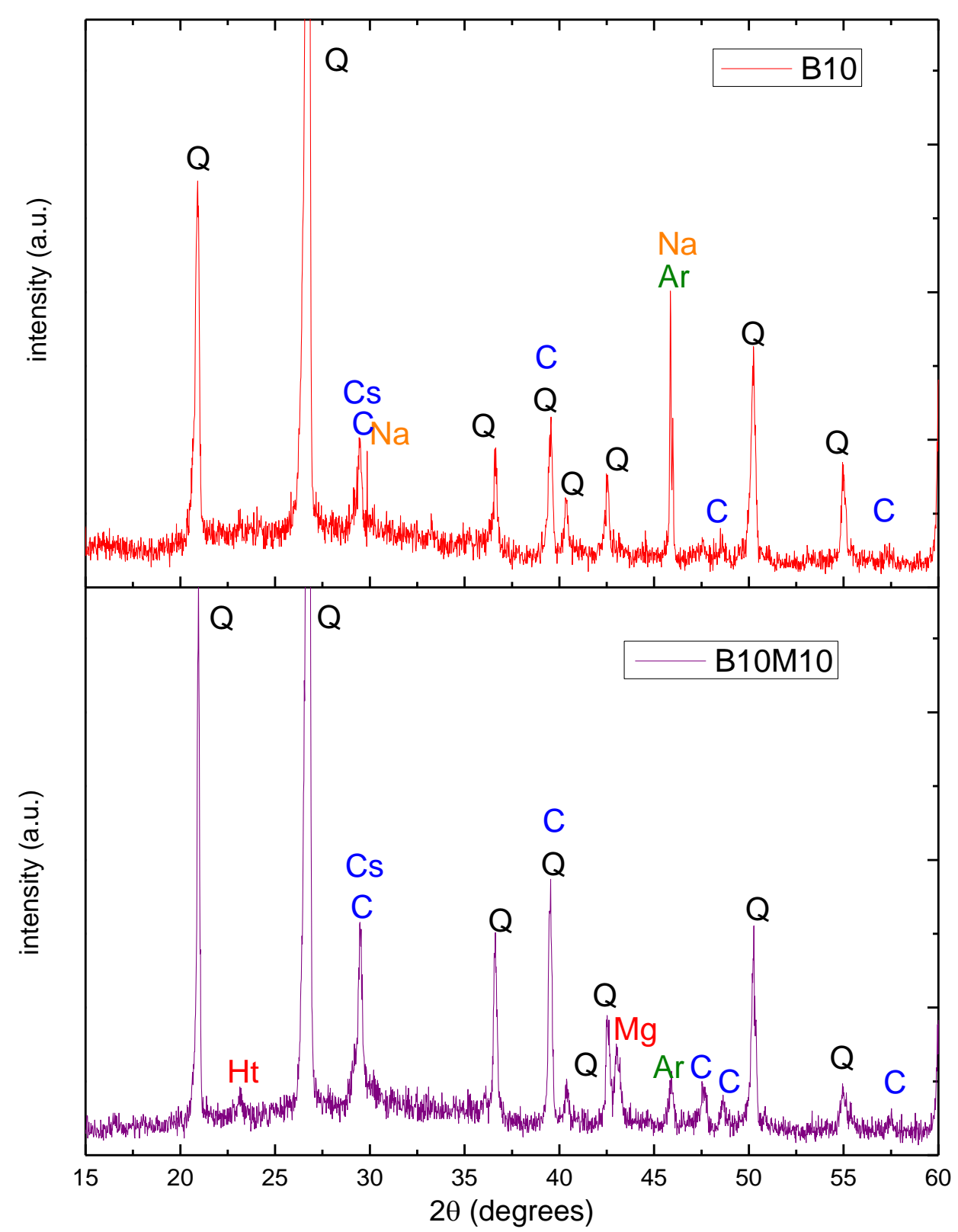

Figure 9 PXRD patterns of mixes B10 and B10M10 and after immersion in $\mathrm{HCl}$ solution for six months, where Ar: Aragonite; C: Calcite; Cs: C-A-S-H; Ht: Hydrotalcite; Mg: MgO; Na: $\mathrm{NaCl}$; Q: Quartz 
The DTG curves of the concrete samples after immersion in $\mathrm{HCl}$ solution are shown in Figure 10. The first peak is observed at a temperature of $\sim 100{ }^{\circ} \mathrm{C}$ indicating the removal of evaporable water which is present in the pores of the gel products (marked as C-S-H). A shoulder just below $200{ }^{\circ} \mathrm{C}$ is attributed to the dehydration of the calcium-rich silicate gel. At the location marked with $\mathrm{Ht}$, small peaks at 250 and $350{ }^{\circ} \mathrm{C}$ in the sample are assigned to the dehydration and dihydroxylation of $\mathrm{Ht}$, respectively. This phase was identified by PXRD but seems to be most prominent in B10M10 due to the presence of a higher MgO content. At approximately $650-675^{\circ} \mathrm{C}$, mass loss peaks were observed in all samples, attributed to the decomposition of the carbonate minerals. The variations in the decomposition temperature of this phase between samples may indicate the presence of different structural forms of carbonates, in particular poorly crystalline or amorphous forms, in the binding matrix. The total weight loss of mix B10 after exposure was $\sim 7 \%$ while the weight loss of mix B10M10 after exposure was $\sim 16 \%$.

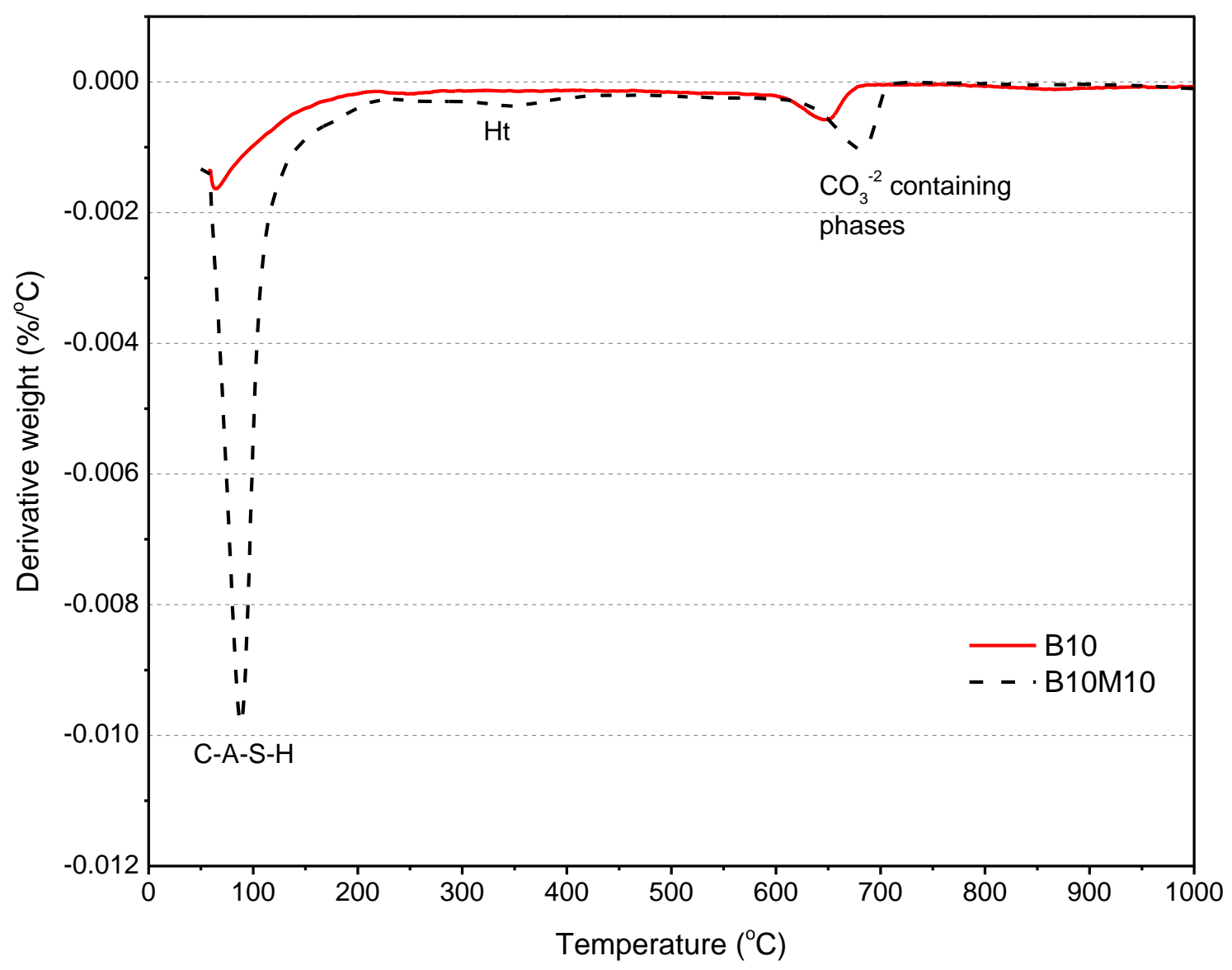

Figure 10 DTG analysis of mixes B10 and B10M10 after immersion in $\mathrm{HCl}$ solution for six months. 


\subsection{Carbonation resistance}

Mixes A10, B10, B10-SP and B10M10 were used to study the effect of the accelerated carbonation on the performance of NC-SF concrete. The physical conditions of samples after exposure did not indicate any level of deterioration. The carbonation penetration area of the specimens is shown in Table 6 and the average carbonation depth values are presented in Figure 11. It was clear from the photos that, before applying the phenolphthalein solution, there were two distinctive colours of the binding matrix. The green colouration corresponding to the noncarbonated area and consistent with the presence of reduced sulphur species in the parts of the materials which have not been exposed to oxygen [52]. The beige colouration relates to the oxidised regions and corresponds to carbonated areas. After the application of the indicator, there was a graduation in purple colouration as the outer part (carbonated region) was much lighter in colour compared to the inner part (non-carbonated region).

Table 6 Transverse sections of accelerated carbonated samples after 70 days, with the extent of carbonation depth revealed by the phenolphthalein indicator.

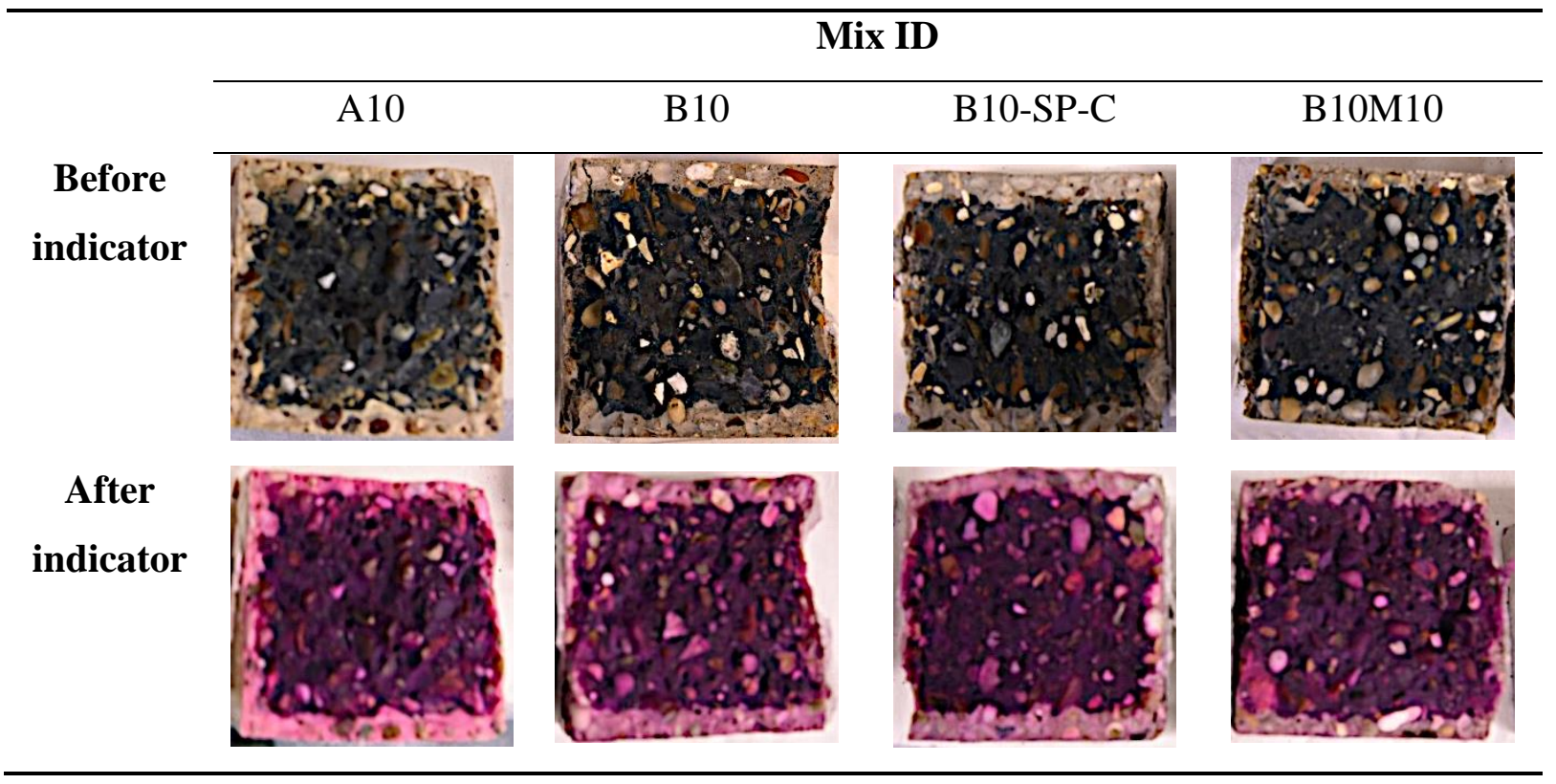

The average carbonation depth of the samples varied from just less than $7.0 \mathrm{~mm}$ to $\sim 9.5 \mathrm{~mm}$. The lowest carbonation depth was found for sample B10M10. These results are slightly higher than those observed in PC concrete and AAS concrete after 10 weeks of accelerated carbonation at 3\% $\mathrm{CO}_{2}$ and $70 \% \mathrm{RH}$ [53], although the results are not directly comparable due to the different $\mathrm{CO}_{2}$ concentration and $\mathrm{RH}$ employed. The trend of the carbonation depth was similar to what was observed for the water absorption of the same samples: the inclusion of fly 
ash and SP led to an increase in the carbonation depth while the incorporation of reactive $\mathrm{MgO}$ substantially decreased the carbonation depth. The inclusion of fly ash resulted in higher water absorption values, indicating a higher permeability of mixes containing fly ash. The reduced carbonation depth of the mix containing reactive $\mathrm{MgO}$ could be attributed to the reduced porosity, hindering the ingress of $\mathrm{CO}_{2}$ in the specimens. Moreover, the presence of reactive $\mathrm{MgO}$ favours the formation of $\mathrm{Ht}$, which can absorb $\mathrm{CO}_{2}$ and improve the carbonation resistance of the binder [52].

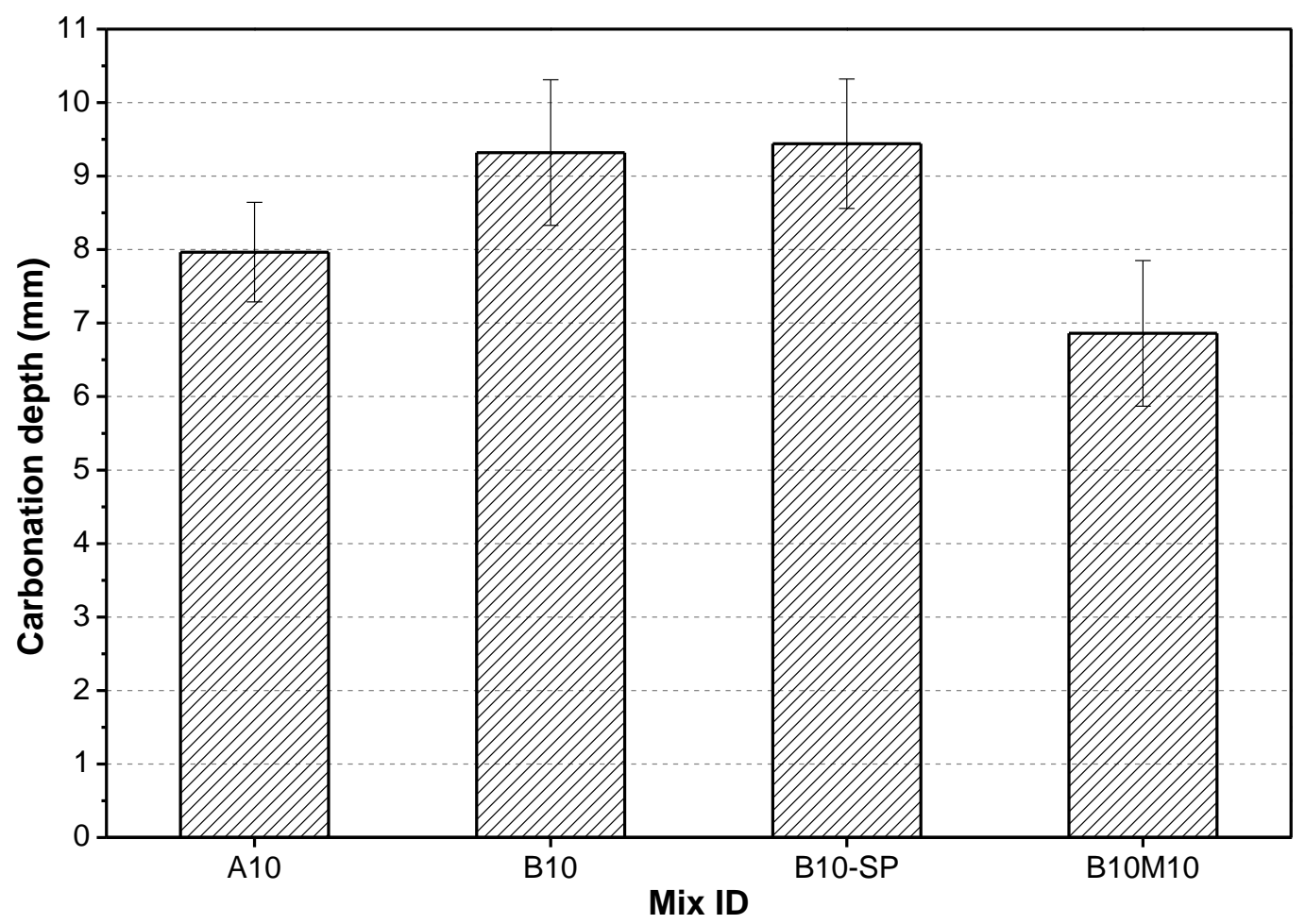

Figure 11 Carbonation depth of A10, B10, B10M10 and B10-SP samples after exposure to accelerated carbonation for 70 days $\left(4.0 \pm 0.5 \% \mathrm{CO}_{2}, 20 \pm 2{ }^{\circ} \mathrm{C}\right.$ and $\left.55 \pm 5 \% \mathrm{RH}\right)$.

It was found that there was no difference in the samples' weight before and after exposure (not shown). The changes in the compressive strength after the carbonation process are summarised in Table 7. It shows that upon accelerated carbonation for 70 days, the carbonated samples continued to gain strength by $20-40 \%$ after 28 days similar to non-carbonated samples, which were left in sealed curing. The difference of the strength between exposed and unexposed samples at the end of the exposure time was negligible. These findings confirm that the $\mathrm{CO}_{2}$ was not able to penetrate into the samples and change the binding paste, thus changing the weight and the strength of the samples. In alkali-activated slag materials, carbonation typically leads to a substantial decrease in the compressive strength [54] as a result of the decalcification of the main binding phase, the C-A-S-H type gel, along with an increase in permeability. 
However, this study suggests that the kinetics and impacts of carbonation is governed by the high alkalinity of the pore solution generated in the binders. It is likely that the carbonation of the pore solution and precipitation of carbonation products led to the blockage of the pores, hindering the ingress of $\mathrm{CO}_{2}$ in the specimens and decreasing the permeability of the system [55].

Table 7 The strength of A10, B10, B10M10 and B10-SP concrete samples before and after exposure to $\mathrm{CO}_{2}$ for 70 days $\left(4.0 \pm 0.5 \% \mathrm{CO}_{2}, 20 \pm 2{ }^{\circ} \mathrm{C}\right.$ and $\left.55 \pm 5 \% \mathrm{RH}\right)$.

\begin{tabular}{cccc}
\hline Mix ID & 28-day UCS (MPa) & $\begin{array}{c}\text { UCS of unexposed samples } \\
\text { (112-day strength) }\end{array}$ & $\begin{array}{c}\text { UCS after exposure } \\
\text { (MPa) }\end{array}$ \\
\hline A10 & 59.12 & 78.82 & 82.52 \\
B10 & 56.09 & 71.1 & 71.05 \\
B10-SP & 58.12 & 68.29 & 69.09 \\
B10M10 & 60.92 & 76.52 & 76.75 \\
\hline
\end{tabular}

PXRD diffractograms of the carbonated specimens (B10 and B10M10) before and after exposure are shown in Figure 12. In both mixes, the calcium carbonate polymorphs calcite (C), vaterite (V) and aragonite (Ar) were identified. Their presence in the sample before and after exposure in both carbonated area and non-carbonated area is consistent with the carbonation of the Ca-rich phases present in this binder and/or as reaction products upon the activation by NC. Higher intensity peaks of vaterite and aragonite were observed in carbonated areas. The formation of the hydrous sodium carbonates phases such as nahcolite $\left(\mathrm{NaHCO}_{3}, \mathrm{PDF} \#\right.$ 00-015$0700)$, thermonatrite $\left(\mathrm{NaCO}_{3} \cdot \mathrm{H}_{2} \mathrm{O}, \mathrm{PDF} \#\right.$ 01-072-0578) and natron $\left(\mathrm{Na}_{2} \mathrm{CO}_{3} \cdot 10 \mathrm{H}_{2} \mathrm{O}, \mathrm{PDF} \#\right.$ 00-015-0800) were detected, associated with the carbonation of the pore solution. The presence of gaylussite $(\mathrm{G})$ was also detected in samples before and after exposure. The main difference between the PXRD patterns of $\mathrm{B} 10$ and $\mathrm{B} 10 \mathrm{M} 10$ is the presence of reactive $\mathrm{MgO}$ peak $(\mathrm{Mg})$ and a higher intensity peak of $\mathrm{Ht}$. Ht have the capacity to absorb $\mathrm{CO}_{2}[56]$ and therefore it could be expected that the formation of these phases contributes to the enhanced resistance of these binders when exposed to high $\mathrm{CO}_{2}$ concentrations. The peak of $\mathrm{Mg}$ in the carbonated area was lower than that in non-carbonated area, indicating that the possibility of the carbonation of the reactive $\mathrm{MgO}$ to form magnesium carbonate products [57]. However, due to the overlapping between peaks and the difficulty of separating the sand from the samples, the peak of quartz dominated and clear conclusion cannot be drawn from the PXRD analysis. 


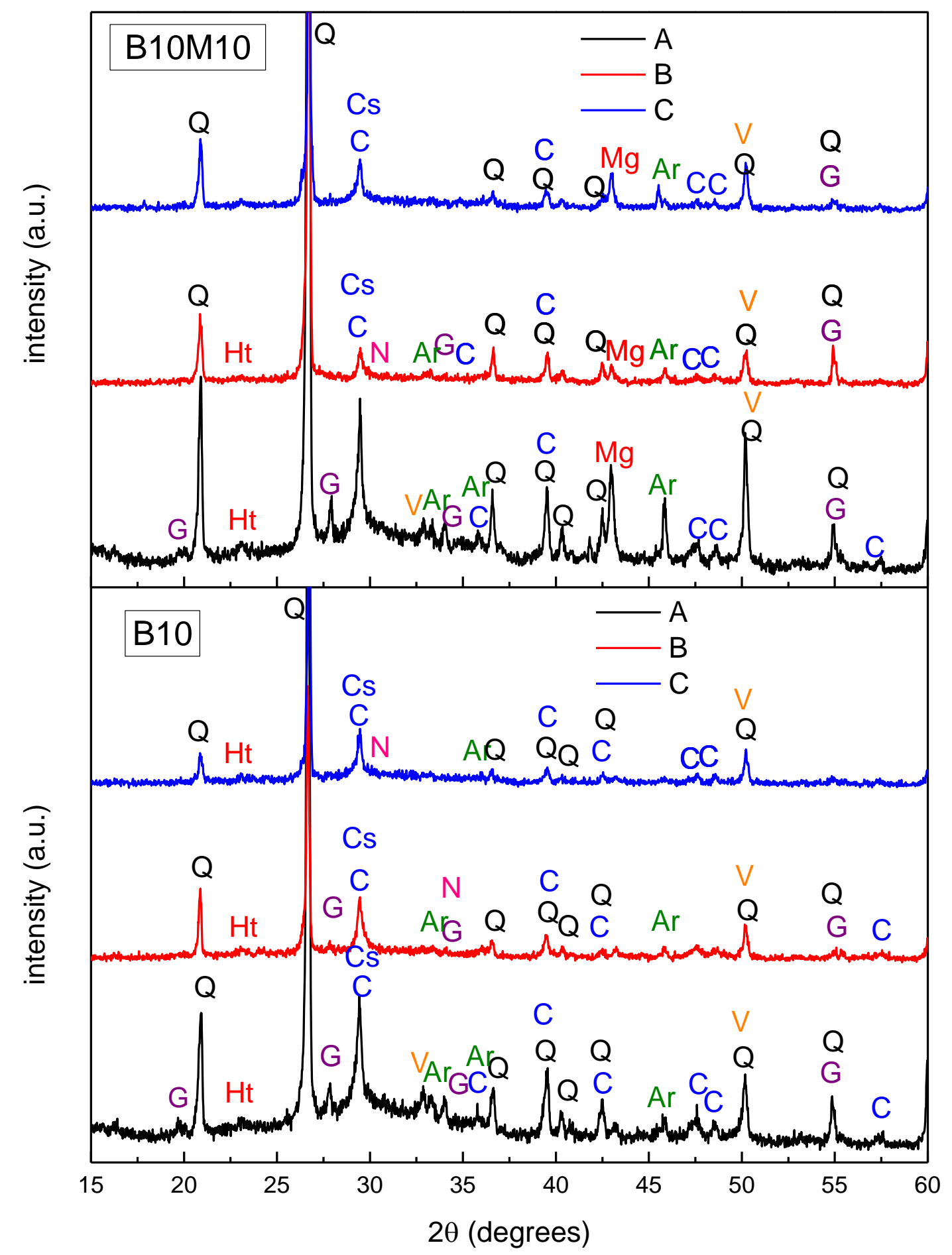

Figure 12 PXRD pattern of mix B10 (Bottom) and mix B10M10 (Top): (A) noncarbonated area after exposure; (B) carbonated area after exposure; and (C) before exposure to accelerated carbonation for 70 days, where Ar: Aragonite; C: Calcite; Cs: C-A-S-H; G: gaylussite; Ht: Hydrotalcite; Mg: MgO; N: Nahcolite; Q: Quartz; V: Vaterite. 
Figure 13 shows the DTG results for samples B10 and B10M10. The unexposed samples (black solid lines in the graph) demonstrated four main peaks: (i) a peak positioned at $\sim 120{ }^{\circ} \mathrm{C}$ corresponds to the dehydration of $\mathrm{C}-\mathrm{S}-\mathrm{H}$; (ii) a peak centred at $\sim 365{ }^{\circ} \mathrm{C}$ is assigned to the dihydroxylation of $\mathrm{Al}$ in $\mathrm{Ht}$; (iii) a peak at $\sim 480{ }^{\circ} \mathrm{C}$ refers to the decomposition of poorly crystalline calcium carbonate phases such as vaterite and aragonite; and (iv) a peak located at $\sim 700{ }^{\circ} \mathrm{C}$ corresponds to the decomposition of calcite. These results are typical of their cement paste counterparts discussed in [14,19]. The main differences between the two mixes were on the middle peaks. B10M10 displayed a higher Ht peak and a lower poorly crystalline calcium carbonate, which could be due to the $\mathrm{CO}_{2}$ uptake for the formation of $\mathrm{Ht}$-like phases, thereby decreasing the availability of $\mathrm{CO}_{2}$ to form $\mathrm{CaCO}_{3}$.

After exposure, both the carbonated and non-carbonated regions were analysed. Both mixes showed that the DTG results of carbonated regions (red dashed lines) differed from those of non-carbonated regions (blue dotted lines). In the latter, the third peak, assigned to poorly crystalline $\mathrm{CaCO}_{3}$, disappeared in both mixes, indicating the transformation of this phase to more crystalline phase. Conversely, this peak increased in the carbonated regions, which implies that the exposure to $\mathrm{CO}_{2}$ led to the formation of poorly crystalline $\mathrm{CaCO}_{3}$. This is consistent with the findings of [58] who showed that, due to kinetics effect, the metastable $\mathrm{CaCO}_{3}$ polymorphs vaterite and aragonite will form first and will then convert to calcite as the reaction time extends.

Table 8 shows the weight loss in two temperature ranges: $100-500{ }^{\circ} \mathrm{C}$ and $500-1000{ }^{\circ} \mathrm{C}$. The first temperature range is associated with the dehydration of the reaction products. The weight loss at temperatures from 500 to $1000{ }^{\circ} \mathrm{C}$ is due to decarbonation. The results suggest that the non-carbonated regions in both samples tested (B10 and B10M10) demonstrated a higher weight loss between 100 and $500{ }^{\circ} \mathrm{C}$ than carbonated regions. Conversely, the weight loss between 500 and $1000{ }^{\circ} \mathrm{C}$ of non-carbonated regions was lower than that of carbonated regions. This could indicate that a decalcification of the C-A-S-H gel had taken place and carbonbearing products formed. The reduction of the reaction products in the first range and the increase of the reaction products in the carbonated regions were higher in B10 than in B10M10. This means that the carbonation was more intense in B10 than in B10M10, consistent with the carbonation depth results. 


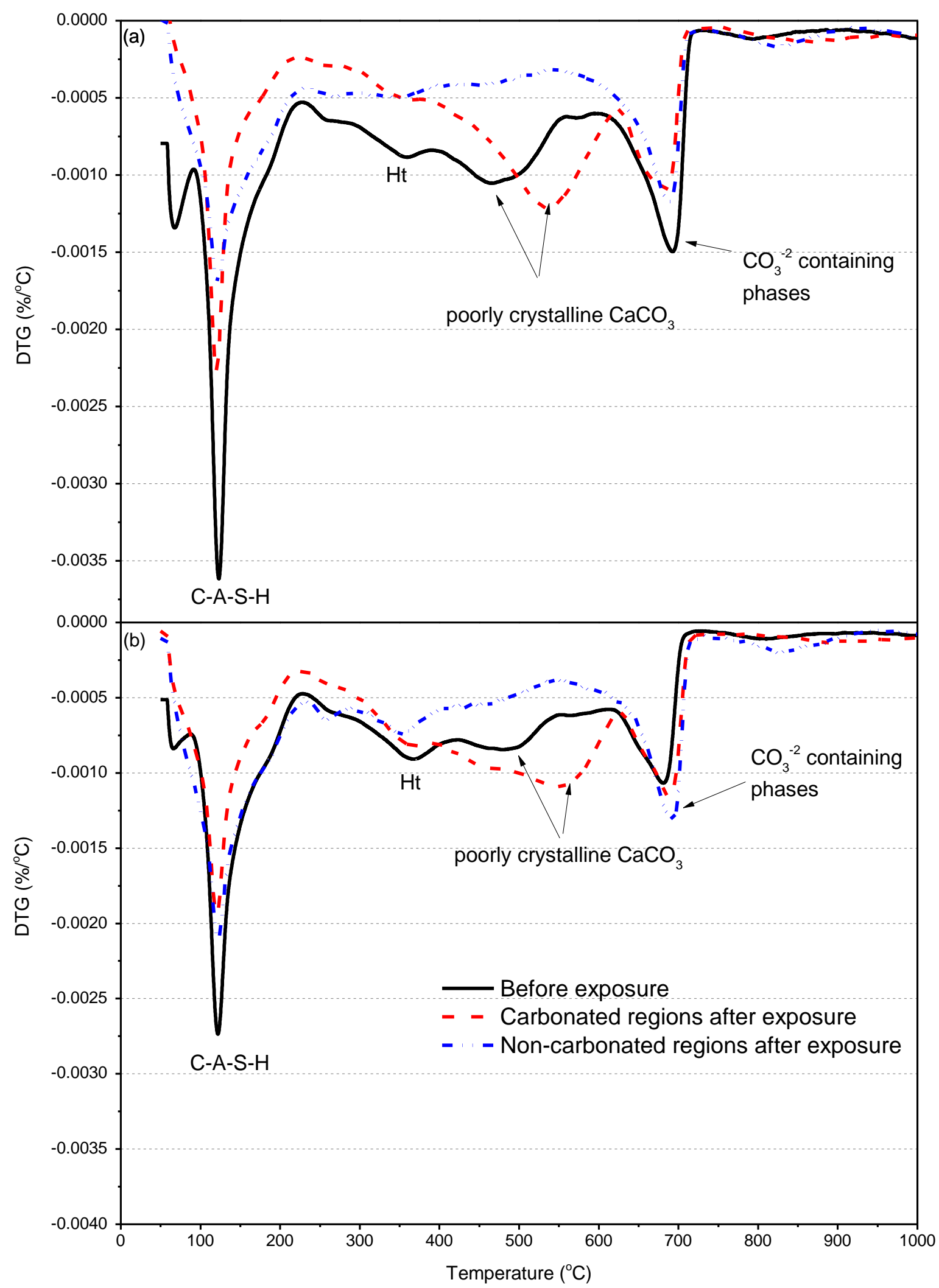

Figure 13 DTG curves of some mixes before and after exposure to the accelerated carbonation conditions for 70 days: (a) B10; and (b) B10M10. 
Table 8 Weight losses of non-carbonated and carbonated areas of B10 and B10M10 concrete samples after exposure to accelerated carbonation for 70 days.

\begin{tabular}{ccccc}
\hline & \multicolumn{4}{c}{ Weight loss (\%) } \\
\cline { 2 - 5 } Mix ID & \multicolumn{2}{c}{$\mathbf{1 0 0 - 5 0 0}{ }^{\circ} \mathbf{C}$} & \multicolumn{2}{c}{$\mathbf{5 0 0 - 1 0 0 0}{ }^{\circ} \mathbf{C}$} \\
\cline { 2 - 5 } & Non-carbonated & Carbonated & Non-carbonated & Carbonated \\
& $(\%)$ & $(\%)$ & $(\%)$ & $(\%)$ \\
\hline B10 & 7.30 & 6.47 & 4.19 & 5.90 \\
B10M10 & 7.82 & 7.67 & 4.08 & 5.55 \\
\hline
\end{tabular}

\subsection{Elevated-temperature resistance}

Visual examination, shown in Table 9, of the concrete samples after exposure to high temperatures showed that all specimens developed shrinkage cracking after the exposure. This shrinkage cracking significantly increased with the increase of the temperature from 500 to 800 ${ }^{\circ} \mathrm{C}$. No spalling was observed on the surface of any of the concrete cylinders although the surfaces turned into a brown colour after exposure, indicating the oxidisation of iron from the raw materials.

The variation of the compressive strength of the selected specimens is shown in Figure 14. After the exposure to a temperature of $500{ }^{\circ} \mathrm{C}$, the residual strength ranged between 19 and $27 \%$. The highest residual strength was observed for the control mix. A further reduction in the compressive strength was observed with increasing the temperature to $800{ }^{\circ} \mathrm{C}$.

Guerrieri and Sanjayan [59] reported that NS-activated S/F pastes demonstrated strength losses by $90 \%$ after exposure to $800{ }^{\circ} \mathrm{C}$. The convergence of the results between the different samples in this study could be explained by the fact that the strength loss in AAS concrete at high temperatures depends mainly on the thermal incompatibility between the binder and the aggregates [60].

PXRD patterns of mixes B10 and B10M10 are shown in Figure 15. The main crystalline phases in the samples before high-temperature exposure were discussed in the previous sections. After the exposure to $500{ }^{\circ} \mathrm{C}$, various mineralogical transformations occurred. Firstly, the peak of the low crystalline $\mathrm{CaCO}_{3}$, aragonite (observed at $37.9^{\circ} 2 \theta$ ), significantly decreased corresponding to the transformation of this phase to more crystalline phase such as calcite. Secondly, the peak 
assigned to gaylussite disappeared confirming the decomposition of this phase at this temperature. Finally, a new phase corresponding to wollastonite $\left(\mathrm{CaSiO}_{3}, \mathrm{PDF} \#\right.$ 04-010-2581) formed as can be seen at $23.2^{\circ} 2 \theta$ and $25.3^{\circ} 2 \theta$ (denoted " $\mathrm{W}$ ' in Figure 15). The latter phase results from the dehydration of the main binding phase, the C-A-S-H gel.

Table 9 Visual examination of concrete samples after exposure to 500 or $800{ }^{\circ} \mathrm{C}$.

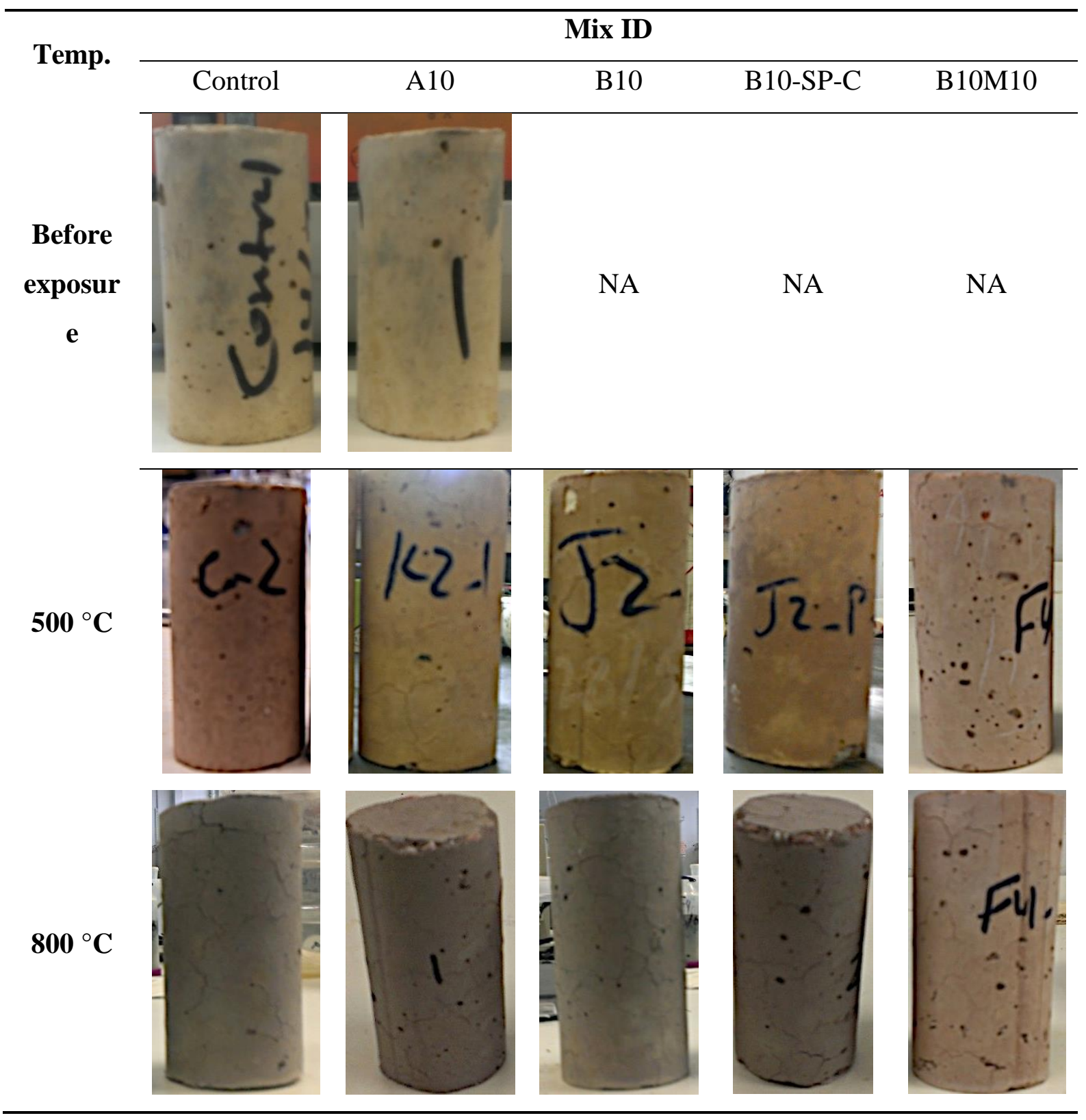

NA: Not available. 


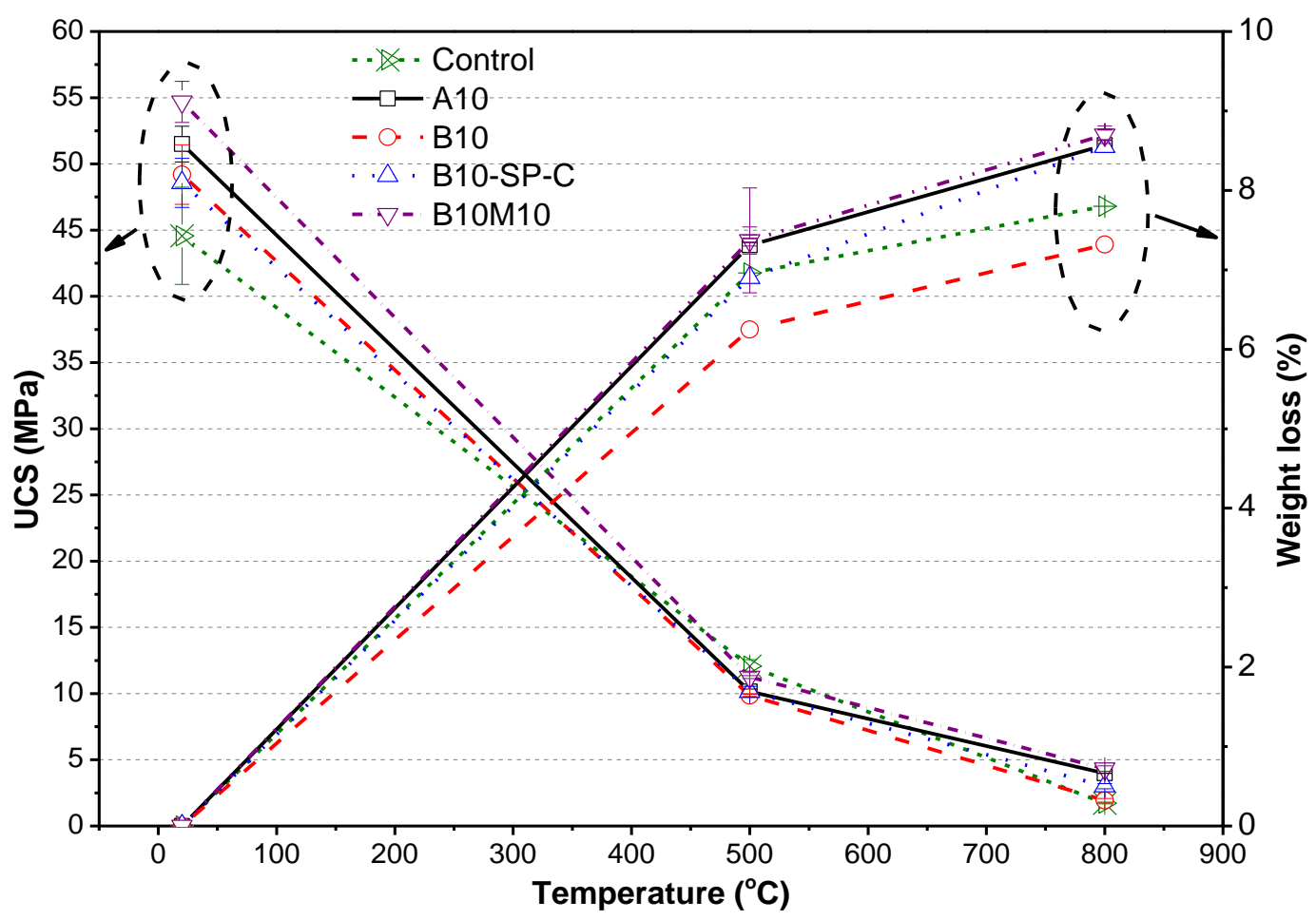

Figure 14 Compressive strength and weight loss of concrete specimens at 500 or $800{ }^{\circ} \mathrm{C}$

At $800^{\circ} \mathrm{C}$, more mineralogical changes took place. The peak of the C-A-S-H type gel disappeared, indicating the transformation of the amorphous phase into more ordered phases. The PXRD patterns of all samples demonstrated that akermanite $\left(\mathrm{Ca}_{2} \mathrm{Mg}\left[\mathrm{Si}_{2} \mathrm{O}_{7}\right], \mathrm{PDF} \# 00-\right.$ 035-0592, denoted as A) became a predominant crystalline phase. However, other crystalline phases such as magnesite $\left(\mathrm{MgCO}_{3}\right.$, denoted $\left.\mathrm{M}\right)$, calcite, wollastonite, diopside $\left(\mathrm{CaMgSi}_{2} \mathrm{O}_{6}\right.$; PDF\# 00-075-0192, denoted D) and spinel ( $\mathrm{MgAl}_{2} \mathrm{O}_{4}$; PDF\# 00-054-0964,

denoted S) were evident. The latter could result from the decomposition of the Ht. It is reported that a porous structure based on akermanite can be beneficial to high-temperature application because akermanite has a very high thermal stability [61]. These findings are comparable to other studies $[62,63]$. 


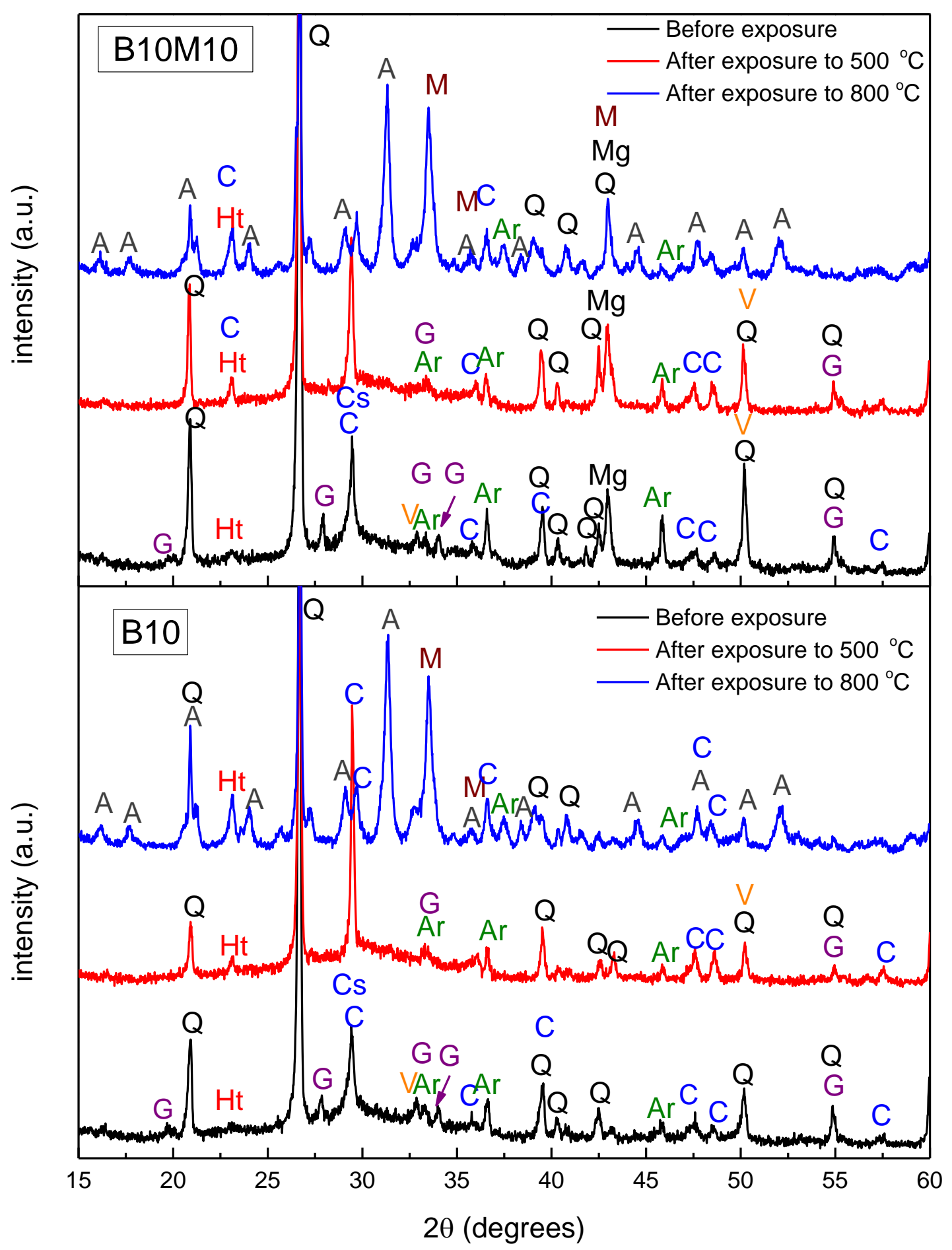

Figure 15 PXRD patterns of mix B10 (Bottom) and mix B10M10 (Top): (a) before exposure to elevated-temperature, (b) after exposure to $500{ }^{\circ} \mathrm{C}$ and (c) after exposure to $800{ }^{\circ} \mathrm{C}$, where A: Akermanite, Ar: Aragonite; C: Calcite; Cs: C-A-S-H; D: Diopside; G: gaylussite; Ht: Hydrotalcite-like phases; M: magnesite; Mg: MgO; N: Nahcolite; Q: Quartz; S: Spinel; V: Vaterite; W: Wollasonite 
The infrared spectra of the specimens collected at room temperature on cooled samples after exposure to temperatures of 500 and $800{ }^{\circ} \mathrm{C}$ and the unexposed specimen for mix B10M10 are illustrated in Figure 16. In the unexposed specimens, the main broad band at $950 \mathrm{~cm}^{-1}$ is assigned to asymmetric stretching vibration of $\mathrm{Si}-\mathrm{O}$ bonds. It refers to the main binding $\mathrm{C}-\mathrm{A}$ $\mathrm{S}$-H type gel. The band at $1650 \mathrm{~cm}^{-1}$ and the wide band centred at $3400 \mathrm{~cm}^{-1}$ correspond to the terminal $\mathrm{OH}$ groups in the matrix and free water molecules, respectively. The band at $1405 \mathrm{~cm}^{-}$ ${ }^{1}$ and the shoulder at $871 \mathrm{~cm}^{-1}$ refer to the carbonation products in the paste. The bands at 775 $\mathrm{cm}^{-1}$ and $800 \mathrm{~cm}^{-1}$ refer to external ring vibrations formed when $\mathrm{AlO}_{4}$ and $\mathrm{SiO}_{4}$ tetrahedral are linked by oxygen atoms. They were likely produced by the quartz forming part of $\mathrm{F}$, but also by the sand-quartz forming part of the concrete and not completely removed from samples [64]. When the specimen subjected to $500{ }^{\circ} \mathrm{C}$, the intensity of the diffuse band at $3400 \mathrm{~cm}^{-1}$ and the band at $1650 \mathrm{~cm}^{-1}$ disappeared due to the release of both the free and constitutional water from the structure of the paste. The intensity of peaks related to carbonate species was reduced at this temperature indicating the start of the decomposition of these species. Slight changes occurred in Si-O-T network as the peak at $950 \mathrm{~cm}^{-1}$ broadened and slightly shifted to a lower wavelength.

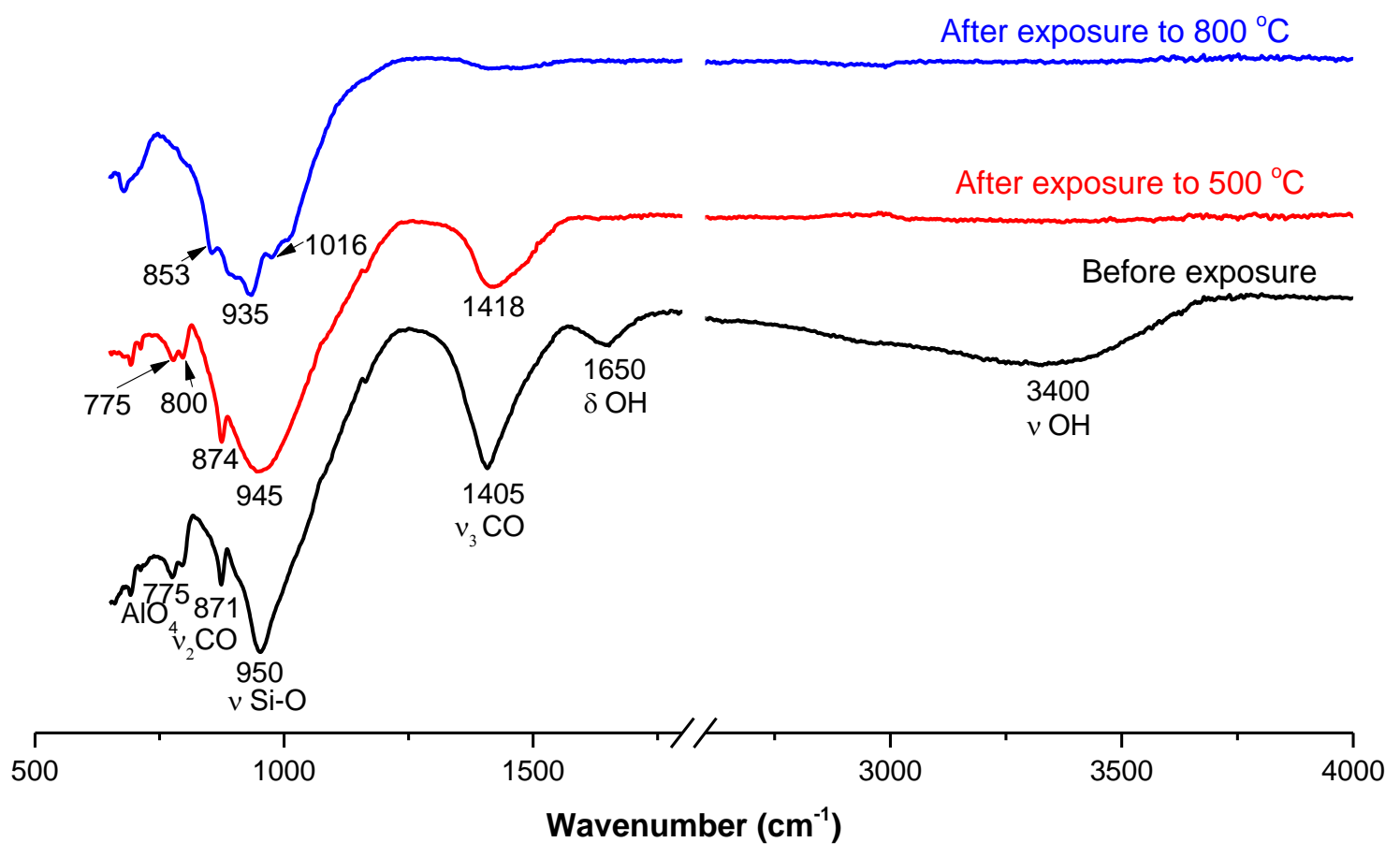

Figure 16 FTIR spectra of the B10M10 after exposure to 500 or $800{ }^{\circ} \mathrm{C}$, depicted in the transmittance mode. 
Increasing the exposure temperature to $800{ }^{\circ} \mathrm{C}$ resulted in remarkable structural transformations. The peaks at around $1405 \mathrm{~cm}^{-1}$ and $871 \mathrm{~cm}^{-1}$ significantly decreased due to the decomposition of the carbonate phases, which started at $500{ }^{\circ} \mathrm{C}$ and almost completely finished at $800{ }^{\circ} \mathrm{C}$. Significant structural changes were observed in the region between 800 and $1100 \mathrm{~cm}^{-1}$. The band centered at $950 \mathrm{~cm}^{-1}$ split into three bands at 853,935 and $1016 \mathrm{~cm}^{-1}$, with a shoulder at $880 \mathrm{~cm}^{-1}$. This implies that the structure became highly crystalline after heating to this temperature, in agreement with PXRD results. These new bands can be associated with vibrations of the silicate skeleton in crystalline akermanite. The intensive band at $935 \mathrm{~cm}^{-1}$ represents a stretching mode of the non-bridging oxygens in the disilicate group [62].

\section{Conclusion}

The mechanical and durability properties of sodium carbonate activated slag/fly ash (NC-SF) concrete mixes were examined and showed promising results. The main conclusions can be listed as follows:

- The mechanical strengths of the concrete samples developed over time, with ultimate compressive strength of 60-75 MPa and splitting tensile strength of 4.5-5 MPa after 90 days. There were no significant differences in compressive strength and splitting tensile strength values between samples after long curing time (90 days). However, at early ages, the incorporation of reactive $\mathrm{MgO}$ and the superplasticiser (SP) led to higher mechanical strengths while the addition of fly ash did not affect these strengths.

- It was found that the water absorption values of all samples were slightly higher than the control sample. The water absorption values of all samples ranged between 3.5 and $5 \%$. This value increased with the addition of fly ash and SP while it decreased with the incorporation of reactive $\mathrm{MgO}$. The concrete samples in this study outperformed the control sample after the immersion in $5 \% \mathrm{Na}_{2} \mathrm{SO}_{4}, 5 \% \mathrm{MgSO}_{4}$ and $1 \% \mathrm{HCl}$ solutions for 6 months. Samples immersed in both sulphate solutions did not show any sign of deterioration and retained their initial compressive strengths. In contrast, after immersion in $\mathrm{HCl}$ solution, degradation in the compressive strength of all samples was observed, with loss values ranging between 23-53\%. This was accompanied with a detectable corroded layer of 2-7.5 mm. The addition of fly ash resulted in less resistant concrete to acid attack while the incorporation of reactive $\mathrm{MgO}$ improved the acid resistance. Sample B10M10 exhibited the highest resistance to acid attack. 
- The performance of the concrete samples after the exposure to accelerated carbonation (4\% $\mathrm{CO}_{2}$ for 70 days) indicated that all samples were high resistant to accelerated carbonation. After the exposure, all samples demonstrated increased compressive strength values, which were compared to the unexposed samples. Moreover, the carbonation depth varied from 7 to $9.5 \mathrm{~mm}$. The carbonation depth slightly increased with the addition of fly ash and decreased with the inclusion of reactive $\mathrm{MgO}$. The improvement of the carbonation resistance due to the inclusion of reactive $\mathrm{MgO}$ is likely because the gel chemistry effects.

- In this study, the concrete samples exposed to high temperatures demonstrated high level of disintegration, cracking and strength loss. The strength and weight losses increased as the firing temperature increased. Severe microstructural changes take place after exposure to high temperatures. These changes, in addition to the thermal incompatibility between the binding phase and the aggregate, resulted in poor performance of the concrete sample after the exposure to elevated-temperatures.

These findings indicated that NC-SF concrete mixes develop acceptable mechanical strengths and demonstrate high resistance to sulphate attack. They also showed higher resistance to acid attack than the sodium silicate-activated slag concrete. Here, emphasis is placed on the potential of developing NCSF binders with excellent performance and less complicated production methods as well as a low carbon footprint compared to conventional alkali-activated materials (AAMs). This, in turns, will contribute to the efforts to develop greener AAMs and promote the uptake of such binders.

\section{Acknowledgements}

The authors would like to thank the Yousef Jameel Foundation and the Cambridge Commonwealth, European and International Trust for their financial support of this research. The help of Dr. Tahreer Fayyad is highly acknowledged.

\section{References}

[1] E. Gartner, Industrially Interesting Approaches to "Low-CO2" Cements, Cem. Concr. Res. 34 (2004) 1489-1498. doi:10.1016/j.cemconres.2004.01.021.

[2] J.L. Provis, J.S.J. van Deventer, eds., Alkali Activated Materials, Springer Netherlands, Dordrecht, 2014. doi:10.1007/978-94-007-7672-2.

[3] J.L. Provis, S.A. Bernal, Geopolymers and related alkali-activated materials, Annu. 
Rev. Mater. Res. 44 (2014) 299-327. doi:10.1146/annurev-matsci-070813-113515.

[4] S. Kumar, R. Kumar, S.P. Mehrotra, Influence of granulated blast furnace slag on the reaction, structure and properties of fly ash based geopolymer, J. Mater. Sci. 45 (2010) 607-615. doi:10.1007/s10853-009-3934-5.

[5] S. Puligilla, P. Mondal, Role of slag in microstructural development and hardening of fly ash-slag geopolymer, Cem. Concr. Res. 43 (2013) 70-80. doi:10.1016/j.cemconres.2012.10.004.

[6] S.K. Nath, S. Kumar, Influence of iron making slags on strength and microstructure of fly ash geopolymer, Constr. Build. Mater. 38 (2013) 924-930. doi:10.1016/j.conbuildmat.2012.09.070.

[7] S. Chithiraputhiran, N. Neithalath, Isothermal reaction kinetics and temperature dependence of alkali activation of slag, fly ash and their blends, Constr. Build. Mater. 45 (2013) 233-242. doi:10.1016/j.conbuildmat.2013.03.061.

[8] C. Shi, R.L. Day, Early strength development and hydration of alkali-activated blast furnace slag/fly ash blends, Adv. Cem. Res. 11 (1999) 189-196. doi:10.1680/adcr.1999.11.4.189.

[9] C.-T. Chen, H.-A. Nguyen, T.-P. Chang, T.-R. Yang, T.-D. Nguyen, Performance and microstructural examination on composition of hardened paste with no-cement SFC binder, Constr. Build. Mater. 76 (2015) 264-272. doi:10.1016/j.conbuildmat.2014.11.032.

[10] X. Gao, Q.L. Yu, H.J.H. Brouwers, Reaction kinetics, gel character and strength of ambient temperature cured alkali activated slag-fly ash blends, Constr. Build. Mater. 80 (2015) 105-115. doi:10.1016/j.conbuildmat.2015.01.065.

[11] A.M. Rashad, Properties of alkali-activated fly ash concrete blended with slag, Iran. J. Mater. Sci. Eng. 10 (2013) 57-64.

[12] X. Hu, C. Shi, Z. Shi, L. Zhang, Compressive strength, pore structure and chloride transport properties of alkali-activated slag/fly ash mortars, Cem. Concr. Compos. (2019). doi:10.1016/j.cemconcomp.2019.01.010. 
[13] R. Gopalakrishnan, K. Chinnaraju, Durability of ambient cured alumina silicate concrete based on slag/fly ash blends against sulfate environment, Constr. Build. Mater. 204 (2019) 70-83. doi:10.1016/j.conbuildmat.2019.01.153.

[14] A.F. Abdalqader, F. Jin, A. Al-Tabbaa, Characterisation of reactive magnesia and sodium carbonate-activated fly ash/slag paste blends, Constr. Build. Mater. 93 (2015). doi:10.1016/j.conbuildmat.2015.06.015.

[15] A. Abdalqader, A. Al-Tabbaa, Factors affecting the properties of Na2CO3-activated fly ash/slag paste, in: 34th Annu. Cem. Concr. Sci. Conf., University of Sheffield, Sheffield, UK, 2014: pp. 329-332.

[16] A. Abdalqader, A. Al-Tabbaa, Mechanical and Microstructural Characterisation of Multicomponent Blended Cements Incorporating Reactive Magnesia, in: Proceeding 1st Concr. Innov. Cnference (CIC), Oslo, The Norwegian Concrete Association Norsk Betongforening, Oslo, 2014: p. 93.

[17] A. Abdalqader, A. Al-Tabbaa, Rheological properties of sodium carbonate-activated fly ash/slag pastes with different superplasticisers, in: 27th Bienn. Natl. Conf. Concr. Inst. Aust. Conjunction with 69th RILEM Week, 2015: p. 1583.

[18] A. Abdalqader, A. Al-Tabbaa, Sustainable binder based on sodium carbonate-activated fly ash/slag and reactive magnesia, in: 2015 Int. Concr. Sustain. Conf., National Ready Mixed Concrete Association, 2015: pp. 1-15. http://www.nrmcaevents.org/?nav=display\&file=787.

[19] A.F. Abdalqader, F. Jin, A. Al-Tabbaa, Development of greener alkali-activated cement: Utilisation of sodium carbonate for activating slag and fly ash mixtures, J. Clean. Prod. 113 (2016) 66-75. doi:10.1016/j.jclepro.2015.12.010.

[20] G. Ishwarya, B. Singh, S. Deshwal, S.K. Bhattacharyya, Effect of sodium carbonate/sodium silicate activator on the rheology, geopolymerization and strength of fly ash/slag geopolymer pastes, Cem. Concr. Compos. (2019). doi:10.1016/j.cemconcomp.2018.12.007.

[21] C.C. Ban, T.L. Ee, M. Ramli, The engineering properties and microstructure of sodium carbonate activated fly ash/ slag blended mortars with silica fume, Compos. Part B 
Eng. 160 (2019) 558-572. doi:10.1016/j.compositesb.2018.12.056.

[22] S.A. Bernal, J.L. Provis, R.J. Myers, R. San Nicolas, J.S.J. van Deventer, Role of carbonates in the chemical evolution of sodium carbonate-activated slag binders, Mater. Struct. (2014) 1-13. doi:10.1617/s11527-014-0412-6.

[23] S.A. Bernal, X. Ke, J.L. Provis, Activation of slags using near-neutral salts: the importance of slag chemistry, in: C. Shi, Y. Yao (Eds.), 14th Int. Congr. Chem. Cem. (ICCC 2015), Beijing, China, 2015.

[24] F. Jin, A. Al-Tabbaa, Strength and drying shrinkage of slag paste activated by sodium carbonate and reactive $\mathrm{MgO}$, Constr. Build. Mater. 81 (2015) 58-65. doi:10.1016/j.conbuildmat.2013.10.081.

[25] F. Jin, K. Gu, A. Al-Tabbaa, Strength and drying shrinkage of reactive MgO modified alkali-activated slag paste, Constr. Build. Mater. 51 (2014) 395-404. doi:10.1016/j.conbuildmat.2013.10.081.

[26] W. Shen, Y. Wang, T. Zhang, M. Zhou, J. Li, X. Cui, Magnesia modification of alkaliactivated slag fly ash cement, J. Wuhan Univ. Technol. Sci. Ed. 26 (2011) 121-125. doi:10.1007/s11595-011-0182-8.

[27] F. Jin, K. Gu, A. Al-Tabbaa, Strength and hydration properties of reactive MgOactivated ground granulated blastfurnace slag paste, Cem. Concr. Compos. 57 (2015) 8-16. doi:10.1016/j.cemconcomp.2014.10.007.

[28] Y. Fang, J. Liu, Y. Chen, Effect of magnesia on properties and microstructure of alkali-activated slag cement, Water Sci. Eng. 4 (2011) 463-469. doi:10.3882/j.issn.1674-2370.2011.04.010.

[29] L. Pu, C. Unluer, Durability of carbonated $\mathrm{MgO}$ concrete containing fly ash and ground granulated blast-furnace slag, Constr. Build. Mater. 192 (2018) 403-415. doi:10.1016/j.conbuildmat.2018.10.121.

[30] F. Jin, A. Al-Tabbaa, Characterisation of different commercial reactive magnesia, Adv. Cem. Res. 26 (2014) 101-113. doi:10.1680/adcr.13.00004.

[31] S. Wang, K.L. Scrivener, P.L. Pratt, Factors affecting the strength of alkali-activated 
slag, Cem. Concr. Res. 24 (1994) 1033-1043.

[32] BSI, BS EN 12390-3 Testing hardened concrete Part 3: Compressive strength of test specimens, British Standard Institution, UK., (2009).

[33] BSI, BS EN 12390-6 Testing hardened concrete Part 6: Tensile splitting strength of test specimens, British Standard Institution, UK., (2009).

[34] BSI, BS 1881-122 Testing concrete. Method for determination of water absorption, British Standard Institution, UK., (2011).

[35] BSI, BS 1881-210 Determination of the potential carbonation resistance of concrete. Accelerated carbonation method, British Standard Institution, UK., (2013).

[36] BS EN 13295:2004 - Products and systems for the protection and repair of concrete structures.Test methods. Determination of resistance to carbonation, 2004. https://shop.bsigroup.com/ProductDetail/?pid=000000000030105144 (accessed April 20, 2019).

[37] L.T. Phan, N.J. Carino, Review of mechanical properties of HSC at elevated temperature, J. Mater. Civ. Eng. 10 (1998) 58-65. doi:10.1061/(ASCE)08991561(1998)10:1(58).

[38] F. Collins, J.G. Sanjayan, Workability and mechanical properties of alkali activated slag Concrete, Cem. Concr. Res. 29 (1999) 455-458. doi:10.1016/S00088846(98)00236-1.

[39] F. Collins, J.. Sanjayan, Effects of ultra-fine materials on workability and strength of concrete containing alkali-activated slag as the binder, Cem. Concr. Res. 29 (1999) 459-462. doi:10.1016/S0008-8846(98)00237-3.

[40] H. Xu, J.L. Provis, J.S.J. Van Deventer, P. V Krivenko, Characterization of aged slag concretes, ACI Mater. J. 102 (2008) 131-139.

[41] C. Shi, D. Roy, P. Krivenko, Alkali-Activated Cements and Concretes, Taylor \& Francis, Oxon, 2006.

[42] M. Kovtun, E.P. Kearsley, J. Shekhovtsova, Chemical acceleration of a neutral 
granulated blast-furnace slag activated by sodium carbonate, Cem. Concr. Res. 72 (2015) 1-9. doi:10.1016/j.cemconres.2015.02.014.

[43] M.A. Yazdi, M. Liebscher, S. Hempel, J. Yang, V. Mechtcherine, Correlation of microstructural and mechanical properties of geopolymers produced from fly ash and slag at room temperature, Constr. Build. Mater. 191 (2018) 330-341. doi:10.1016/j.conbuildmat.2018.10.037.

[44] P.S. Deb, P. Nath, P.K. Sarker, The effects of ground granulated blast-furnace slag blending with fly ash and activator content on the workability and strength properties of geopolymer concrete cured at ambient temperature, Mater. Des. 62 (2014) 32-39. doi:10.1016/j.matdes.2014.05.001.

[45] S.A. Bernal, R. Mejía de Gutiérrez, A.L. Pedraza, J.L. Provis, E.D. Rodriguez, S. Delvasto, Effect of binder content on the performance of alkali-activated slag concretes, Cem. Concr. Res. 41 (2011) 1-8. doi:10.1016/j.cemconres.2010.08.017.

[46] M. Olivia, H. Nikraz, P. Sarker, Improvements in The Strength and Water Penetrability of Low Calcium Fly Ash Based Geopolymer Concrete, in: Proc. 3rd ACF Int. Conf. - ACF/VCA, Ho Chi Minh City, Vietnam, 2008: pp. 384-391.

[47] P. Dinakar, K.G. Babu, M. Santhanam, Durability properties of high volume fly ash self compacting concretes, Cem. Concr. Compos. 30 (2008) 880-886. doi:10.1016/j.cemconcomp.2008.06.011.

[48] Z. Zhang, Y. Zhu, H. Zhu, Y. Zhang, J.L. Provis, H. Wang, Effect of drying procedures on pore structure and phase evolution of alkali-activated cements, Cem. Concr. Compos. 96 (2019) 194-203. doi:10.1016/j.cemconcomp.2018.12.003.

[49] I. Ismail, S.A. Bernal, J.L. Provis, S. Hamdan, J.S.J. Deventer, Microstructural changes in alkali activated fly ash/slag geopolymers with sulfate exposure, Mater. Struct. 46 (2013) 361-373. doi:10.1617/s11527-012-9906-2.

[50] T. Bakharev, J.G. Sanjayan, Y.B. Cheng, Sulfate attack on alkali-activated slag concrete, Cem. Concr. Res. 32 (2002) 211-216. doi:10.1016/S0008-8846(01)00659-7.

[51] T. Bakharev, Durability of geopolymer materials in sodium and magnesium sulfate 
solutions, Cem. Concr. Res. 35 (2005) 1233-1246.

doi:10.1016/j.cemconres.2004.09.002.

[52] S.A. Bernal, R. San Nicolas, R.J. Myers, R. Mejía de Gutiérrez, F. Puertas, J.S.J. van Deventer, J.L. Provis, $\mathrm{MgO}$ content of slag controls phase evolution and structural changes induced by accelerated carbonation in alkali-activated binders, Cem. Concr. Res. 57 (2014) 33-43. doi:10.1016/j.cemconres.2013.12.003.

[53] T. Häkkinen, The influence of slag content on the microstructure, permeability and mechanical properties of concrete. Part 2 Technical properties and theoretical examinations, Cem. Concr. Res. 23 (1993) 518-530. doi:10.1016/00088846(93)90002-Q.

[54] F. Pacheco-Torgal, J.A. Labrincha, C. Leonelli, A. Palomo, P. Chindaprasirt, eds., Handbook of Alkali-activated Cements, Mortars and Concrete, UK: Woodhead Publishing Limited, 2015.

[55] S.A. Bernal, Effect of the activator dose on the compressive strength and accelerated carbonation resistance of alkali silicate-activated slag/metakaolin blended materials, Constr. Build. Mater. 98 (2015) 217-226. doi:10.1016/j.conbuildmat.2015.08.013.

[56] S.A. Bernal, R. San Nicolas, J.L. Provis, R. Mejía de Gutiérrez, J.S.J. van Deventer, Natural carbonation of aged alkali-activated slag concretes, Mater. Struct. 47 (2014) 693-707. doi:10.1617/s11527-013-0089-2.

[57] C. Unluer, A. Al-Tabbaa, The role of brucite, ground granulated blastfurnace slag, and magnesium silicates in the carbonation and performance of $\mathrm{MgO}$ cements, Constr. Build. Mater. 94 (2015) 629-643. doi:10.1016/j.conbuildmat.2015.07.105.

[58] S. Bernal, J.L. Provis, D.G. Brice, A. Kilcullen, P. Duxson, J.S.J. van Deventer, Accelerated carbonation testing of alkali-activated binders significantly underestimates service life: The role of pore solution chemistry, Cem. Concr. Res. 42 (2012) 13171326. doi:10.1016/j.cemconres.2012.07.002.

[59] M. Guerrieri, J.G. Sanjayan, Behavior of combined fly ash/slag-based geopolymers when exposed to high temperatures, Fire Mater. 34 (2010) 163-175. doi:10.1002/fam. 
[60] D.L.Y. Kong, J.G. Sanjayan, Effect of elevated temperatures on geopolymer paste, mortar and concrete, Cem. Concr. Res. 40 (2010) 334-339. doi:10.1016/j.cemconres.2009.10.017.

[61] L. Zuda, P. Rovnanik, P. Bayer, R. Cerny, Thermal properties of alkali-activated slag subjected to high temperatures, J. Build. Phys. 30 (2007) 337-350. doi:10.1177/1744259106075234.

[62] P. Rovnaník, P. Bayer, P. Rovnaníková, Characterization of alkali activated slag paste after exposure to high temperatures, Constr. Build. Mater. 47 (2013) 1479-1487. doi:10.1016/j.conbuildmat.2013.06.070.

[63] L. Zuda, Z. Pavlík, P. Rovnaníková, P. Bayer, R. Černý, Properties of alkali activated aluminosilicate material after thermal load, Int. J. Thermophys. 27 (2006) 1250-1263. doi:10.1007/s10765-006-0077-7.

[64] A. Fernández-Jiménez, A. Palomo, Composition and microstructure of alkali activated fly ash binder: Effect of the activator, Cem. Concr. Res. 35 (2005) 1984-1992. doi:10.1016/j.cemconres.2005.03.003. 